\title{
How to Acquire Cardiac Volumes for Sonographic Examination of the Fetal Heart
} Part 1

\author{
Lami Yeo, MD, Roberto Romero, MD, DMedSci
}

Received January 28, 2016, from the Perinatology Research Branch, Program for Perinatal Research and Obstetrics, Division of Intramural Research, Eunice Kennedy Shriver National Institute of Child Health and Human Development, National Institutes of Health, Bethesda, Maryland, and Detroit, Michigan USA (L.Y., R.R.); Detroit Medical Center, Hutzel Women's Hospital, Detroit, Michigan USA (L.Y.); Department of Obstetrics and Gynecology, Wayne State University School of Medicine, Detroit, Michigan USA (L.Y.); Department of Obstetrics and Gynecology, University of Michigan, Ann Arbor, Michigan USA (R.R.); Department of Epidemiology and Biostatistics, Michigan State University, East Lansing, Michigan USA (R.R.); and Center for Molecular Medicine and Genetics, Wayne State University, Detroit, Michigan USA (R.R.). Manuscript accepted for publication February 29, 2016.

Dr Romero has contributed to this work as part of his official duties as an employee of the United States Federal Government. This article is a US Government work and is in the public domain in the United States. This research was supported in part by the Perinatology Research Branch, Division of Intramural Research, Eunice Kennedy Shriver National Institute of Child Health and Human Development (NICHD), National Institutes of Health (NIH), Department of Health and Human Services; and in part with federal funds from the NICHD, NIH, under contract No. HHSN275201300006C.

Address correspondence to Lami Yeo, $M D$, Perinatology Research Branch, Eunice Kennedy Shriver National Institute of Child Health and Human Development, National Institutes of Health, Department of Health and Human Services, Hutzel Women's Hospital, 3990 John R, 4 Brush, Detroit, MI 48201 USA.

E-mail:lyeo@med.wayne.edu

Abbreviations

CHD, congenital heart disease; $4 D$, 4-dimensional; ROI, region of interest; STIC, spatiotemporal image correlation; 3D, 3-dimensional; 2D, 2-dimensional

doi:10.7863/ultra.16.01081
Four-dimensional sonography with spatiotemporal image correlation (STIC) technology allows acquisition of a fetal cardiac volume data set and displays a cine loop of a complete single cardiac cycle in motion. Part 1 of this 2-part article reviews STIC technology and its features, the importance of operator training/experience, and acquisition of high-quality STIC volumes, as well as factors that affect STIC volume acquisition rates. We also propose a detailed and practical stepwise approach to performing 4dimensional sonography with STIC and begin herein by providing general recommendations. Part 2 will discuss specifics of the approach, along with how to determine whether such volumes are appropriate for analysis.

Key Words - fetal echocardiography; fetus; 4-dimensional; spatiotemporal image correlation; ultrasound

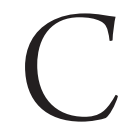
ongenital heart disease (CHD) is the most prevalent organspecific birth defect ${ }^{1}$ and the leading cause of infant morbidity and mortality from congenital malformations. ${ }^{2}$ Prenatal diagnosis of some CHD types is associated with an improved preoperative condition, ${ }^{3-7}$ presurgical mortality rate, ${ }^{8}$ survival after surgery, ${ }^{5,9-12}$ and long-term neurocognitive function and outcome. ${ }^{13,14}$ Yet, despite its importance, sonographic evaluation of the fetal heart is one of the most difficult tasks in prenatal diagnosis.

The detection of CHD is challenging, ${ }^{15,16}$ and the sensitivity of sonography remains low $(22.5 \%-52.8 \%),{ }^{17-21}$ even when more than $90 \%$ of women in population-based studies undergo sonographic examination. This situation has been attributed to the complexity of fetal heart anatomy, cardiac motion, and size. Other factors that affect the prenatal detection of CHD include ${ }^{22,23}$ gestational age at examination, fetal position, maternal obesity, fetal motion, and abnormal amniotic fluid volume. By far, however, the most important factor is operator skill and expertise. ${ }^{24-30}$ Mental reconstruction of a sequence of individual cross-sectional images is required to perform a thorough cardiac examination. ${ }^{31}$

Since volumetric sonography of the fetal heart allows review of all cardiac planes at any time during the cardiac cycle, it could be helpful in cardiac screening. ${ }^{31}$ Four-dimensional (4D) sonography with spatiotemporal image correlation (STIC) technology allows 
the acquisition of a fetal cardiac volume data set and displays a cine loop of a complete single cardiac cycle in motion. Since STIC was first described 13 years ago, ${ }^{32-34}$ studies have demonstrated that volume acquisition can be incorporated into the daily practice of ultrasound centers. ${ }^{35,36}$ Moreover, a large body of evidence suggests that 4D sonography with STIC facilitates examination of the fetal heart $33,34,37-62$ and has the potential to reduce the operator dependency that is associated with conventional 2-dimensional (2D) sonography. Among centers with technical expertise, 4D sonography with STIC has been shown to be an accurate and reliable method for fetal echocardiography in the second trimester, ${ }^{63}$ as well as between 14 and 41 weeks' gestation. ${ }^{64}$ As a result, STIC technology has been used in the prenatal evaluation and diagnosis of $\mathrm{CHD},{ }^{31,32,63-81}$ along with the assessment of fetal cardiac function by combining STIC with Doppler, M-mode, and other postprocessing methods. ${ }^{48,53,82-88}$ Several algorithms based on STIC technology have also been developed $34,37,42,45,54,55,61$ to aid users in systematically and efficiently interrogating volume data sets to display cardiac planes. Other investigators have reported novel automated and semiautomated algorithms using software applied to fetal cardiac volume data sets to successfully generate standard echocardiographic views. ${ }^{89-92}$ This process is especially relevant, since there is a learning curve for the acquisition and analysis of STIC volume data sets. ${ }^{52,93,94}$ Such automation technology has the potential to both standardize and simplify sonographic examinations of the fetal heart by decreasing operator dependency.

Although the clinical value and advantages of 4D sonography with STIC over conventional 2D sonography have been demonstrated, many centers have not embraced this modality ${ }^{95}$ and use only $2 \mathrm{D}$ sonography for fetal cardiac examinations. STIC technology has been widely available on multiple ultrasound platforms in the clinical setting, but it is underused and its value underestimated.

What are the reasons for this? (1) The $x, y$, and $z$ dimensions are not necessarily intuitive, and therefore, volumetric sonography is perceived to be challenging; (2) there exists the view that one should learn the basics of $2 \mathrm{D}$ sonography first, before advancing into other "dimensions"; (3) although 4D sonographic images look artful and impressive, some believe they are mainly for "show" and may not be applicable to one's clinical practice (ie, lack of clinical value); (4) the performance of volumetric sonography is thought to be time-consuming and thus not feasible in a busy clinical practice; (5) there is uncertainty in how to postprocess cardiac volume data sets; (6) not everyone embraces novelty; (7) an unexpressed fear of medical information "hidden" within the volume data set may exist, which could make one vulnerable to blame later; and (8) there is a paucity of training and educational courses on volumetric sonography (especially hands-on).

Although sonologists do not have to be specifically experienced in 3-dimensional (3D) or 4D sonography to acquire high-quality STIC volumes, ${ }^{36}$ they should be adequately trained. If there is a lack of standardization in the acquisition of volume data sets, it would be a major limiting step for the effective performance of fetal cardiac examination using 4D sonography with STIC.

Therefore, in this 2-part article, our main objectives are to: (1) review STIC technology and its characteristic features; (2) discuss the importance of operator training/ experience and acquisition of high-quality STIC volumes; (3) review factors that affect STIC volume acquisition rates; (4) propose a practical and stepwise approach to performing 4D sonography with STIC; and (5) review the evaluation of STIC volumes to determine their appropriateness for analysis. Part 1 focuses on the first 3 objectives, along with general recommendations on performing $4 \mathrm{D}$ sonography with STIC. Part $2^{96}$ provides a detailed and specific approach on steps to be taken before and at STIC volume acquisition, as well as how to determine whether such volumes are appropriate for analysis. We propose that there is a need to demystify $4 \mathrm{D}$ sonography with STIC, so that it is no longer perceived as being too challenging to perform. In this way, the technology can be implemented more widely in fetal cardiac examinations.

\section{STIC Technology}

The term 4-dimensional (or 4D) describes volume data sets that incorporate information about the 3 spatial dimensions and the temporal dimension. ${ }^{97}$ Four-dimensional STIC technology allows acquisition of a fetal cardiac volume data set and visualization of cardiac structures as a cine loop of a complete single cardiac cycle in motion. . $^{32-34,39}$ It is considered an indirect motion-gated offline scanning mode. ${ }^{33,34,41,97,98}$ STIC technology is currently available on multiple ultrasound platforms and is integrated into the system's 3D/4D basic software option. Therefore, no additional software packages for online analysis are required. ${ }^{33}$ Moreover, software packages are also available for offline analysis, which duplicate the online environment.

The principles used by the STIC algorithm to synchronize spatial and temporal information in fetal cardiac volume data sets are similar to that of the nonelectrocardiographic motion Fourier analysis gating method proposed 20 years ago ${ }^{99}$ and have been described 
in detail elsewhere. ${ }^{32-34}$ Nelson et a ${ }^{99}$ were able to gate (synchronize) the spatial and temporal information necessary to display 4D images of the beating fetal heart.

Once STIC has been activated, the array within the transducer begins an automatic single sweep over the predetermined volume, or region of interest (ROI). ${ }^{33,100}$ The STIC volume display comprises thousands of $2 \mathrm{D}$ images acquired through the area of interest during this single automated sweep. The B-mode frame rate during the volume scan can be as high as 150 frames per second ${ }^{33}$; thus, a series of rapidly acquired B-mode images are stacked up behind each other. For example, a 10 -second, $25^{\circ}$ angle of acquisition would contain 1500 B-mode images. ${ }^{33,98}$ Immediately after the STIC volume scan is completed, the system runs a spatial and temporal correlation of the data, detects the systolic peaks, and calculates the fetal heart rate. ${ }^{32,43}$ Frames acquired during the same phase of the cardiac cycle (although from a different position in space) are merged into the same volume data set. ${ }^{101}$ This process is repeated for all phases of the cardiac cycle. Thus, B-mode images are arranged in order according to their spatial and temporal domains (note the term spatiotemporal image correlation). After image rearrangement, an ordered sequence of volume data sets is displayed within seconds on the screen as a continuous cine loop containing all phases of the cardiac cycle, and the data are ready for analysis. ${ }^{33,34}$ Although retrospective, gating is performed immediately after the volume scan while the patient is still on the table, ${ }^{102}$ allowing its integration into clinical use. The STIC volume may be reviewed while the patient is still present; therefore, volume acquisitions may be repeated as necessary. Such volumes can then be saved to the ultrasound machine or to a network.

Although fetal cardiac volume acquisition can also be achieved by using a nongated static 3D approach, neither the heart rate nor motion is considered during acquisition and rendering. As a result, this technique cannot be used to assess events related to the cardiac cycle, as well as myocardial wall and valvular motion. Moreover, the 3D static sweep captures cardiac structures randomly within the cardiac cycle. ${ }^{103}$ Thus, measurements of cardiac and outflow tract dimensions at the end of diastole or systole cannot be performed. In essence, the acquired static 3D volume contains an infinite number of $2 \mathrm{D}$ sonographic planes, but without regard to spatial or temporal motion. There are still, however, several beneficial features of static $3 \mathrm{D}$ volume acquisition of the fetal heart ${ }^{52}:$ (1) rapid acquisition speeds ( $0.5-2$ seconds); (2) the possibility of acquiring large volumes (ROI and acquisition angle), but with minimal artifacts; and (3) such volume data sets may be combined with color Doppler, power Doppler, or B-flow imaging.

\section{Characteristic Features and Applications of 4D Sonography With STIC}

Once the image data are analyzed according to their spatial and temporal domains, the dynamic image sequence can be displayed as a multiplanar reformatted view, single plane, and/or rendered image. ${ }^{33}$ The following describes the characteristic features and applications of 4D sonography with STIC (Table 1). The interested reader is referred to other articles for further review. ${ }^{33}$

1. Three Dimensions - Operators can shift from a 3D mental image reconstruction (which occurs during conventional 2D sonographic examination) to a "true" 3D demonstration of anatomic structures. ${ }^{104}$

2. Temporal Resolution - The dynamic image sequence in the multiplanar or surface-rendered display demonstrates improved temporal resolution ${ }^{33}$ and is attributed to the increased number of $2 \mathrm{D}$ images stored in the STIC volume data set. Thus, a fetal heart that is difficult to image using 2D sonography will become a superior image when viewed with STIC. ${ }^{33}$

3. Operator Dependency - When using 4D sonography with STIC, there is reduced dependency on operator experience and skills to image the fetal heart (which is characteristic of $2 \mathrm{D}$ sonography).

4. Cardiac Volume Data Set_-An operator can navigate within the STIC volume, reslice, and produce all the standard image planes necessary for a diagnosis, either during the clinical examination or in the patient's absence. ${ }^{37,42}$ Other unique characteristics of a cardiac volume data set include:

a. Unlimited number of images: Anatomic structures can be evaluated in different planes of section other than the original acquisition plane.

b. Sequential planes: Real-time 2D sonography allows the sonologist to focus only on a single plane at a time. However, using STIC technology, an operator can view or scroll through multiple cardiac planes in sequence (even within a specific view, such as the 4-chamber view), since there is a volume with $3 \mathrm{D}$ information behind each frame (Video 1). As a result, ventricular septal defects may be identified, for example, which otherwise could have been missed by interrogation of only a single plane of the 4-chamber view.

c. Rotation around $a 360^{\circ}$ axis: Cardiac anatomic structures may be viewed from multiple perspectives.

d. Full independence and control in navigation: During real-time $2 \mathrm{D}$ sonography, the operator is entirely 
dependent on any fetal position changes (which affect cardiac views), movements, and the heart rate. All such factors also affect the duration of the sonographic examination. On the other hand, when navigating through a STIC volume data set, the operator has full independence and control over the fetal "position" (and, thus, cardiac views), the speed of the cine loop (which can be adjusted according to user preference), and the duration of the examination. Moreover, fetal movement is absent during navigation through volumes. Such advantages allow an improved assessment of CHD. ${ }^{64}$

5. Offline Volume Review - Since volume data sets may be reloaded and reviewed at any time, fetal cardiac examinations can be performed even in the patient's

Table 1. Characteristic Features and Applications of 4D Sonography With STIC

\section{Advantages}

1. Three dimensions

2. Temporal resolution

3. Operator dependency

4. Cardiac volume data set

a. Unlimited number of images

b. Sequential planes

c. Rotation around a $360^{\circ}$ axis

d. Full independence and control in navigation

5. Offline volume review

6. Cine loop format

7. Display formats

a. Multiplanar

b. Rendered

8. Virtual planes

9. Repeatability

10. Combination with other applications

11. Congenital heart disease

12. Functional cardiac evaluation

13. Counseling

14. Education and training

15. Telemedicine

\section{Comments}

Operators can shift from a 3D mental image reconstruction to a "true" 3D demonstration of anatomic structures

Resolution is improved due to an increased number of 2D images stored in the STIC volume data set

Reduced dependency on operator experience and skills to image the fetal heart (which is characteristic of 2D sonography)

Operator can navigate within the volume, reslice, and produce all the standard image planes necessary for a diagnosis

Anatomic structures can be evaluated in different planes of section other than the original acquisition plane

Can view or scroll through multiple cardiac planes in sequence (even within a specific view, such as the 4-chamber view)

Cardiac anatomic structures may be viewed from multiple perspectives

Operator has full independence and control over the fetal "position" (and, thus, cardiac views), speed of the cine loop (which can be adjusted according to user preference), and duration of the examination

Fetal cardiac examinations can be performed even in the patient's absence

Allows specific phases of the cardiac cycle (end diastole, end systole) to be analyzed

Allows correlation between image planes that are perpendicular to the main acquisition plane A reference dot tool can be used to manually navigate through the STIC volume data set and localize the same anatomic structure in the 3 orthogonal planes

Allows reconstruction of a $3 \mathrm{D}$ rendered image of the fetal heart that contains depth in the z-plane and provides additional information not available from thin 2D image slices Images of the fetal heart not generally accessible or viewed by using a standard 2D sonographic approach may be obtained

Cardiac structures and measurements in normal fetal hearts have demonstrated high repeatability between (inter), and within (intra) observers

STIC technology can be combined with other applications by selecting the appropriate setting before volume acquisition (eg, color Doppler) or can be combined with postprocessing modalities (eg, inversion mode)

Can improve the ability to identify complex intracardiac relationships

May shorten examination time

Accurate in diagnosing most major structural CHD

Potential to increase the detection rate of $\mathrm{CHD}$

Fetal cardiovascular parameters can be calculated (eg, stroke volume, cardiac output, ejection fraction, TAPSE, ventricular mass, fractional shortening)

Results in improved understanding of CHD by the family

Enhances prenatal counseling and interdisciplinary team consultation/management Useful in both medical education and professional training in fetal echocardiography

Review of STIC volume data sets by other examiners or consultative experts can occur at remote sites

May improve health care delivery systems by extending the benefits of prenatal cardiac screening

TAPSE indicates tricuspid annular plane systolic excursion. 
absence. Moreover, offline review and interpretation of volumes have the potential to improve patient throughput and efficiency of clinical practice..$^{105}$

6. Cine Loop Format_-STIC technology "mimics" a realtime examination of the fetal heart due to its motion characteristics (Video 2). Moreover, the cine loop may be played in slow motion or stopped at any time for a detailed analysis of specific phases of the cardiac cycle. End-diastolic and end-systolic views can be identified by interrogating the STIC volume frame by frame. The speed of the cine loop may also be adjusted based upon user preference.

7. Display Formats

a. Multiplanar display: This format (Figure 1 and Video 2) allows correlation between image planes that are perpendicular to the main acquisition plane (hence, the term multiplanar). Since motion information is preserved with STIC technology, multiple planes of the fetal heart in motion can be visualized and examined simultaneously. ${ }^{50,106-108}$ Each of the scan planes can also be moved and rotated (eg, on the $\mathrm{x}^{-}, \mathrm{y}$-, or $\mathrm{z}$-axis) while maintaining synchronization with the cardiac cycle (Figure 2, A-C, and Videos 3-5). Moreover, in the multiplanar display, the 3 planes intersect at a point. By moving the position of such point (or "reference dot"), the examiner can manually navigate ${ }^{109}$ through the STIC volume data set, and the corresponding planes will change respectively

Figure 1. In this STIC volume, the multiplanar display allows correlation between cardiac planes that are perpendicular to the main acquisition plane. The acquisition plane (apical 4-chamber view) is located in the upper left corner. Notice that the reference dot is located in the descending aorta in all 3 planes.

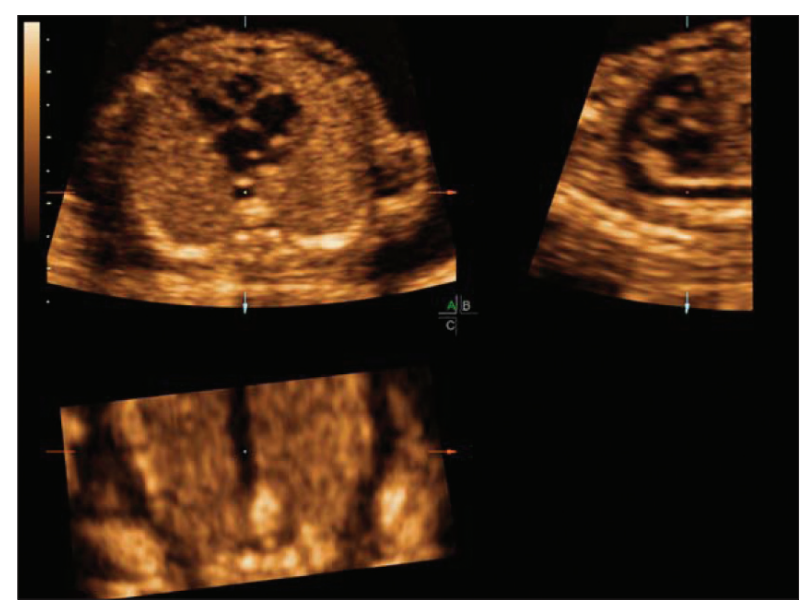

Figure 2. STIC volume of a normal fetal heart. A, The reference dot is located in the crux of the fetal heart, and the acquisition plane has been rotated on the x-axis. Notice that simultaneously, the B plane in the upper right corner (ductal arch in this case) is rotated upward. B. The reference dot is located in the crux of the fetal heart, and the acquisition plane has been rotated rightward on the $y$-axis. Notice that simultaneously, the $B$ and $C$ planes have also changed. $\mathbf{C}$, The reference dot is located in the crux of the fetal heart, and the acquisition plane has been rotated on the $\mathrm{z}$-axis (like a cartwheel). Notice that simultaneously, the $\mathrm{B}$ and $\mathrm{C}$ planes have also changed.
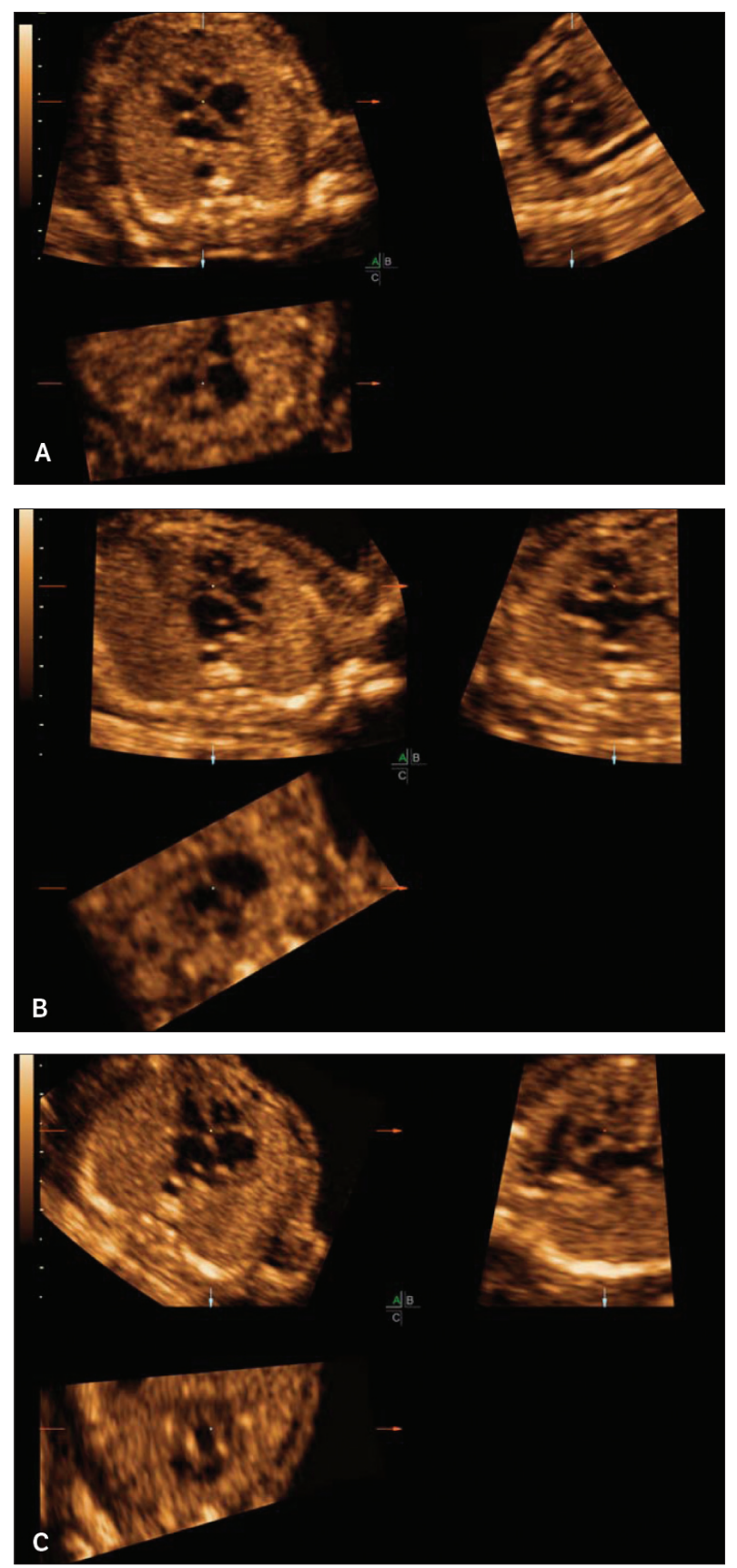
(Figure 3 and Video 6). ${ }^{33}$ The reference dot can also be used to localize the same anatomic structure in the 3 orthogonal planes (eg, right ventricle; Figure 3 and Video 6). Clinical examples in which the multiplanar display has been shown to be useful include examination of the great vessels ${ }^{34}$ and cardiac biometry, ${ }^{110}$ once a specific cardiac structure (eg, ventricular septum) has been obtained in all 3 orthogonal planes.

b. Rendered display: STIC technology allows reconstruction of a 3D rendered image of the fetal heart that contains depth in the z-plane, providing additional information not available from thin 2D image slices (Figure 4 and Video 7). ${ }^{33}$

Figure 3. In the multiplanar view, the reference dot can be used to localize the same anatomic structure (here, the right ventricle) in all 3 orthogonal planes.

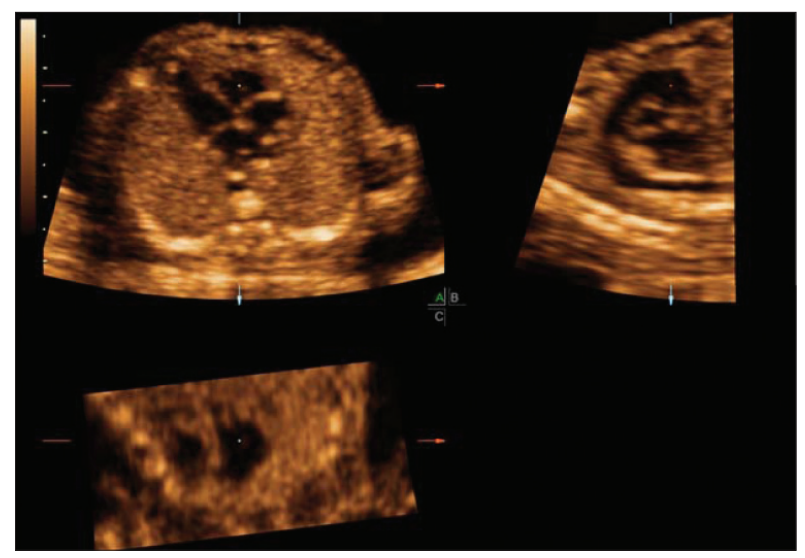

Figure 4. STIC technology allows reconstruction of a 3D rendered image of the fetal heart (here, the 5-chamber view; lower right image) that contains depth in the z-plane. Increased depth allows the posterior wall of the chambers to be viewed simultaneously with the atrioventricular valves.

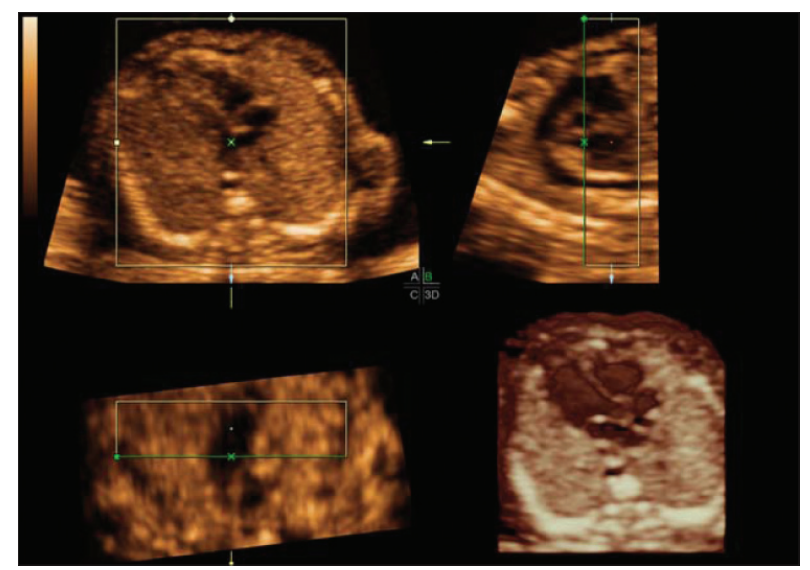

For example, image depth can be altered by the user, so that with decreasing depth, a slice may be isolated. On the other hand, increased depth allows the posterior wall of the cardiac chambers to be viewed simultaneously with the atrioventricular valves.

8. Nonconventional or Virtual Planes - Navigation through a STIC volume allows images of the fetal heart that are not generally accessible or viewed by using a standard 2D sonographic approach (eg, ventricular and atrial septum en face and coronal atrioventricular valve plane $^{111,112}$; Figures 5 and 6 and Videos 8 and 9).

Figure 5. Ventricular septum en face. STIC technology allows visualization of "virtual" planes that are not generally accessible or viewed by using a standard 2D sonographic approach. In the apical 4-chamber view, the green render line is positioned to image the ventricular septum from the right ventricle. The rendered image (ventricular septum en face, triangular in shape) depicted by the white arrow appears realistic, due to the chosen render mode.

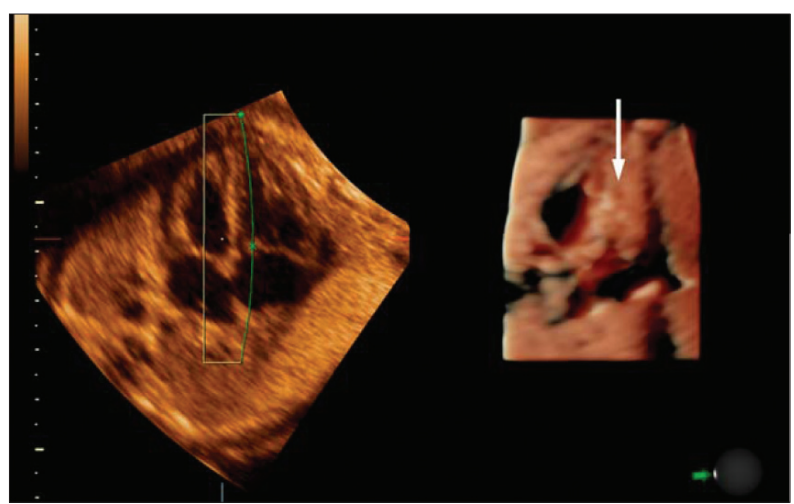

Figure 6. Coronal rendered image of the atrioventricular valves in diastole (STIC volume with color Doppler imaging). In the apical 4-chamber view (upper left corner), the green render line is positioned to image the atrioventricular valves en face from the ventricles. Color Doppler is seen through the open mitral valve (MV) and tricuspid valve (TV).

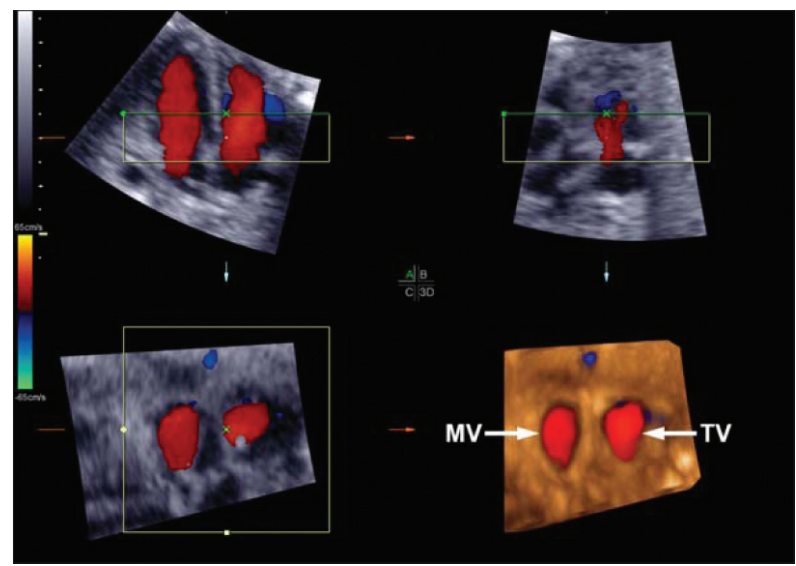


9. Repeatability - Variation in repeated measurements made on the same patient under identical conditions is defined as repeatability of measurements. ${ }^{113}$ Using STIC technology, cardiac structures and measurements in normal fetal hearts have demonstrated high repeatability between (inter), and within (intra) observers. ${ }^{14}$ Moreover, ventricular volume calculations using STIC combined with postprocessing modalities have also been shown to be repeatable and reproducible. ${ }^{115}$

10. Combination With Other Applications-STIC technology can be combined with other applications by selecting the appropriate setting before volume acquisition. These include color Doppler (Figure 7, A and B,

Figure 7. A, Apical 4-chamber view in diastole (STIC volume with color Doppler imaging). The rendered image in the lower right corner shows only color Doppler through the mitral (left) and tricuspid valves (right). B, Apical 4-chamber view in systole (STIC volume with color Doppler imaging). The rendered image in the lower right corner shows color Doppler through the great vessels only (LVOT indicates left ventricular outflow tract; and PA, pulmonary artery). The normal crisscrossing of the great vessels is visualized.
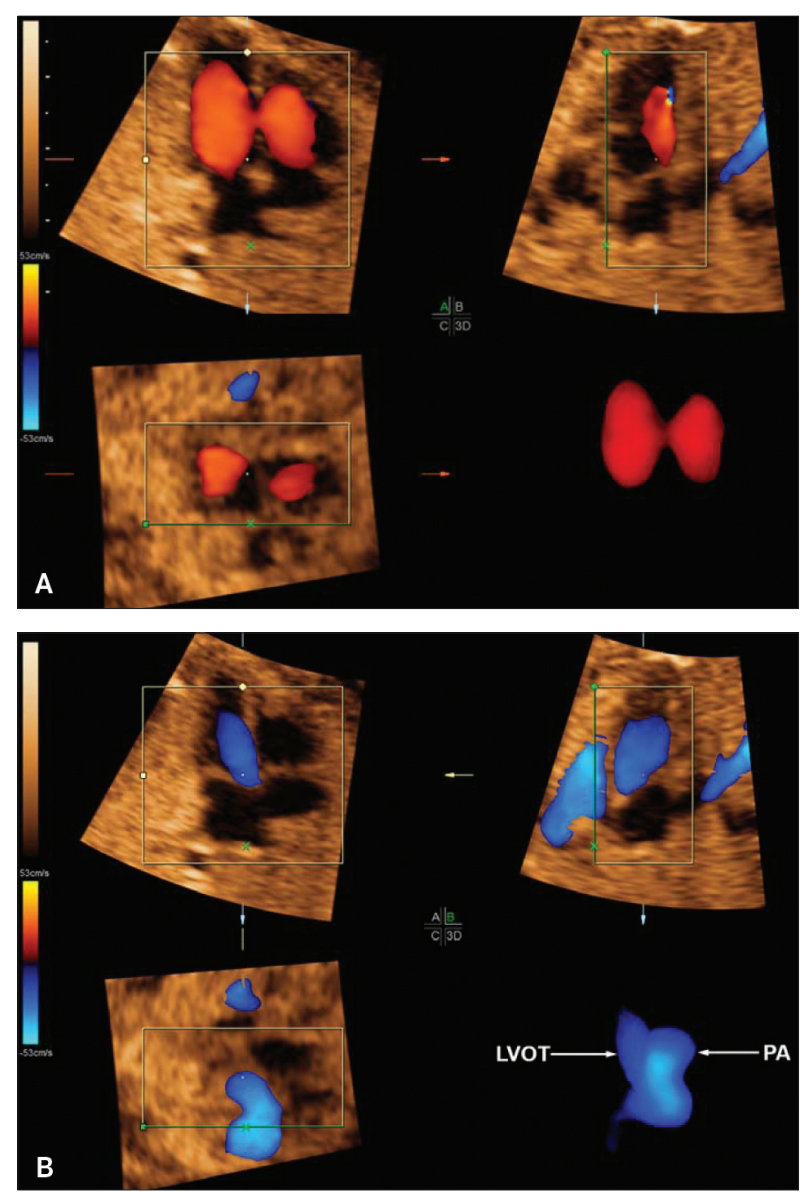

and Videos 10 and 11),,$^{39,40,111}$ power Doppler, ${ }^{66,116}$ high-definition flow Doppler (similar to bidirectional power Doppler), ${ }^{117}$ and B-flow. ${ }^{67,118,119}$ STIC can also be combined with postprocessing modalities, which are not available in the $2 \mathrm{D}$ sonographic mode, including surface rendering, ${ }^{34,112,120}$ inversion mode, ${ }^{65,67}$ and multislice (Figure 8 and Video 12). ${ }^{42,50,106,107}$ The end result is a multitude of display modes for STIC volume data sets.

11. Congenital Heart Disease-Prenatal assessment and diagnosis of $\mathrm{CHD}$ using conventional 2D sonography require an analysis of anatomic structures through a mental reconstruction of their spatial relationships. Four-dimensional sonography with STIC can improve the ability to identify such complex intracardiac relationships (Figure 9 and Video 13) and may also shorten the examination time. ${ }^{33,43,121}$ Moreover, fetal cardiac abnormalities undetected during real-time sonographic examination may be detected at the time of STIC volume review. ${ }^{40} \mathrm{~A}$ high degree of accuracy has been demonstrated when using STIC technology to prospectively evaluate fetuses with a wide spectrum of CHD.${ }^{64}$ Even in the first and early second trimesters, STIC volume evaluation has been shown to be accurate in diagnosing most major structural heart defects. ${ }^{47}$ Therefore, 4D sonography with STIC has the potential to increase the detection rate of $\mathrm{CHD}, 33,62$ and some have proposed its clinical application in cardiac screening and $\mathrm{CHD}$ diagnosis. ${ }^{64}$

Figure 8. Multislice mode applied to a STIC volume data set from a normal fetal heart. Eight transverse sections from the upper mediastinum to the upper abdomen are displayed. In the overview image (ductal arch), the parallel lines indicate the exact position of the planes of section shown in the 8 subsequent images. Note the transverse aortic arch ( -3 image), 3-vessel view (-2 image), 5-chamber view (green asterisk image), 4chamber view (1 image), and stomach (4 image). Also see Video 12.

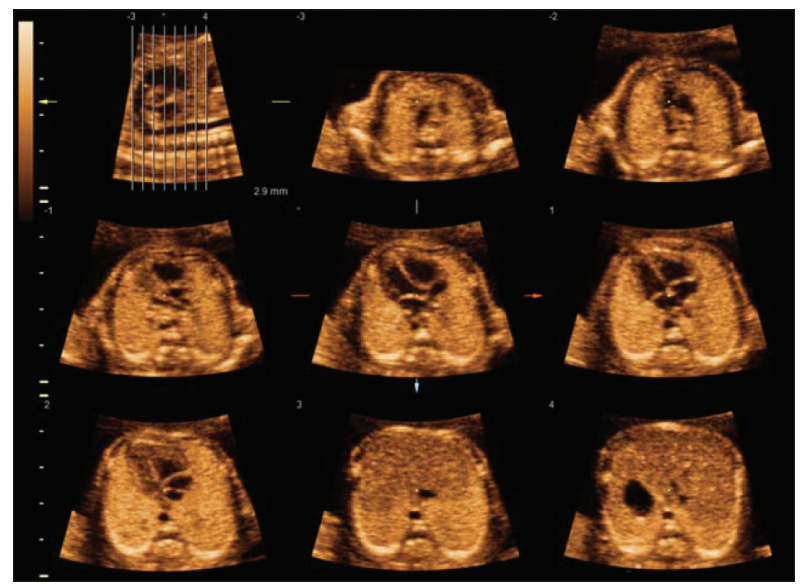


12. Functional Cardiac Evaluation-Within volume data sets, a specific cardiac phase (end diastole or end systole) can be identified by observing the opening and closing of the atrioventricular and semilunar valves. Therefore, by capturing these time points within the cardiac cycle, ventricular volume measurements may be obtained (Figure 10) ${ }^{46}$ and the fetal stroke volume, cardiac output, and ejection fraction calculated. ${ }^{44,48,53,82-84,86,87}$ It is generally agreed that $4 \mathrm{D}$ ventricular volume quantitation is more accurate than

Figure 9. Multiplanar display of a fetus with coarctation of the aorta. The reference dot is located in the transverse aortic arch, which can be confirmed by viewing both the $\mathrm{A}$ (upper left) and $\mathrm{B}$ (upper right) planes. Narrowing of the aortic isthmus is apparent (white arrow).

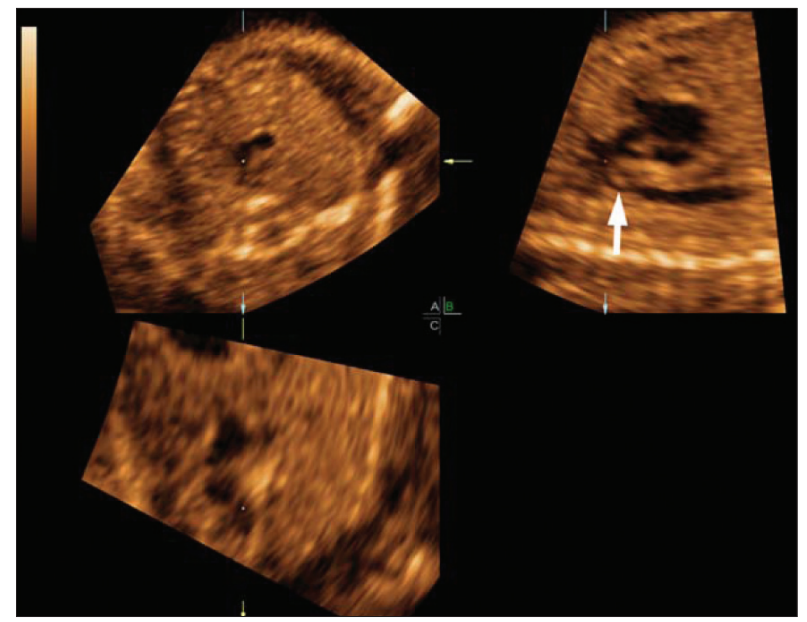

Figure 10. Quantification of fetal left ventricular volume $(2.11 \mathrm{~mL})$ during end diastole. The virtual organ computer-aided analysis (VOCAL) trace was performed in the A plane at the level of the 4-chamber view. The lower right image depicts the 3-dimensional model created by the VOCAL tool, which includes the entire traced volume.

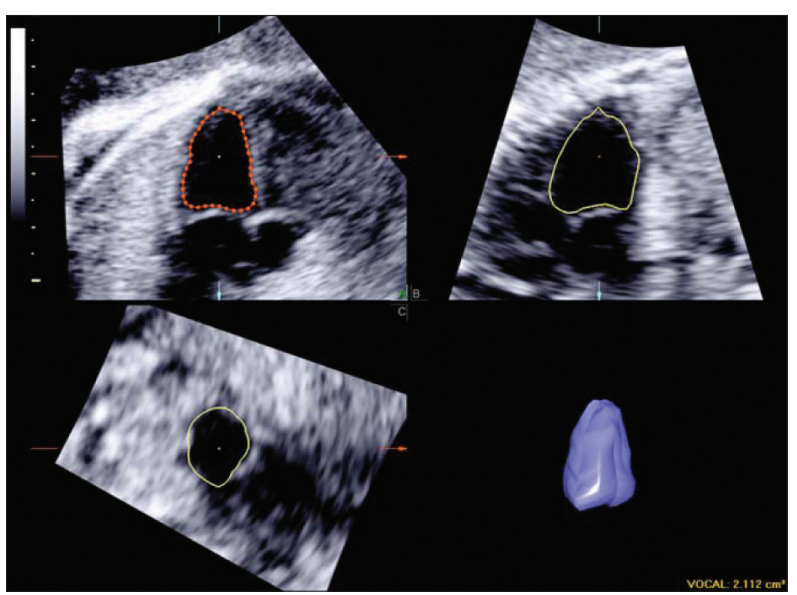

2D-derived methods because geometric assumptions are avoided, along with magnification of small errors (inherent in the latter modality). ${ }^{100,122}$ Thus, $2 \mathrm{D}$ echocardiography has limitations in the assessment of fetal cardiac function. ${ }^{123,124}$ Other fetal cardiovascular parameters [eg, tricuspid annular plane systolic excursion $^{59,125}$ (Figure 11 and Video 14), ventricular mass, ${ }^{85}$ and fractional shortening ${ }^{57}$ (Figure 12 and Video 15)] have also been calculated using STIC technology.

Figure 11. Measurement of STIC M-mode fetal tricuspid annular plane systolic excursion (TAPSE) vertically, parallel to the ventricular septum. The vertical movement of the tricuspid annulus during systole and diastole is derived from measurement $(5.7 \mathrm{~mm})$ of the amplitude of the M-mode wave. This measurement is normal for 25 weeks' gestation. ${ }^{59}$ $\mathrm{RV}$ indicates right ventricle.

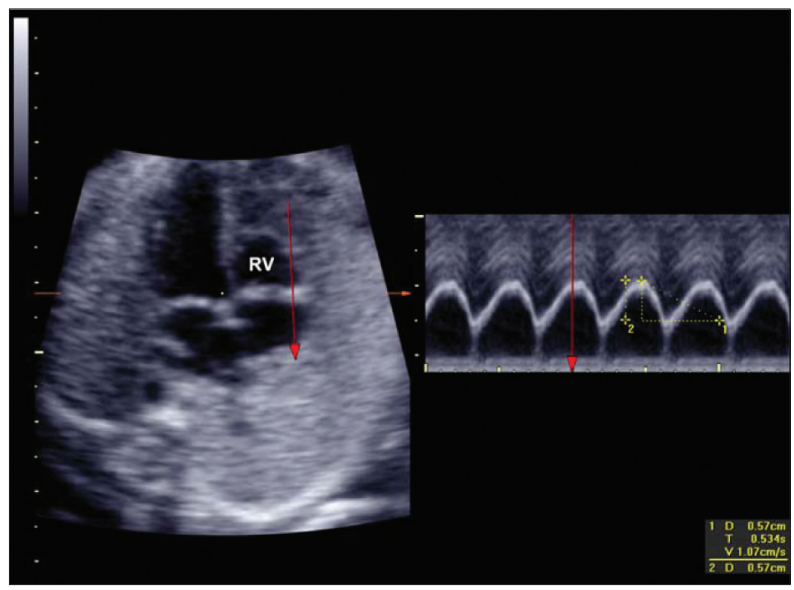

Figure 12. Calculation of fractional shortening using STIC M-mode. The M-mode cursor line is placed perpendicular to the ventricular septum at the level of the mitral and tricuspid valves. From end-diastolic and end-systolic measurements of the ventricles, fractional shortening [(enddiastolic dimension-end-systolic dimension)/end-diastolic dimension)] can be calculated. For the right ventricle, the fractional shortening is $34 \%$ (normal). LV indicates left ventricle; and RV, right ventricle.

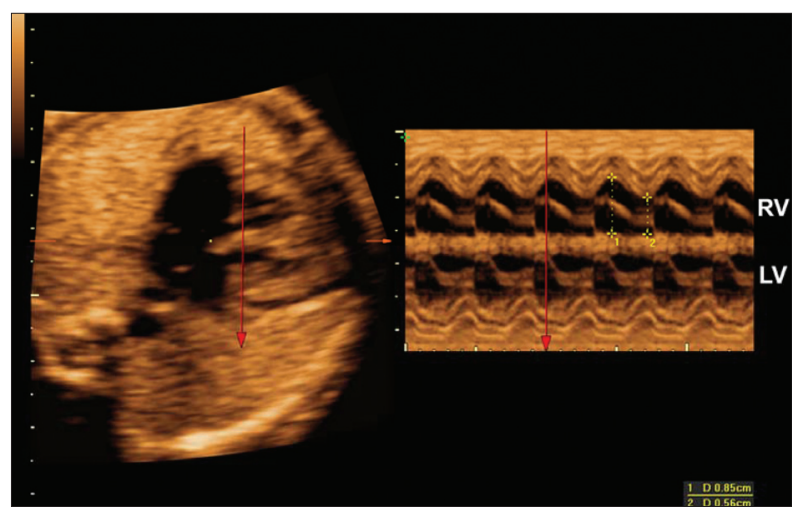


13. Counseling-Four-dimensional sonography with STIC can result in an improved understanding of $\mathrm{CHD}$ by family members. Moreover, prenatal counseling, as well as interdisciplinary team consultation and management can be enhanced.

14. Education and Training-The study and analysis of STIC volume data sets is useful for both medical education and professional training in fetal echocardiography.

15. Telemedicine - Digital storage and review of STIC volume data sets by other examiners or consultative experts can occur at remote sites by transmitting files over networks. ${ }^{32,68,126}$ Such offline networking capabilities may improve health care delivery systems by extending the benefits of prenatal cardiac screening to poorly served or underserved areas. ${ }^{117}$

\section{Importance of Acquiring High-Quality STIC Volumes and Influence of Operator Training/Experience}

\section{Quality of STIC Volumes}

The effective performance of fetal cardiac examination using STIC technology requires 2 essential steps: (1) volume acquisition; and (2) postprocessing. ${ }^{114}$ The quality of a STIC volume data set is essential for postprocessing and assessment. ${ }^{58}$ When the volume data set is suboptimal, subsequent analysis will be hindered by low image quality and artifacts. Indeed, investigators have demonstrated that: (1) the ability to visualize fetal cardiac structures is correlated with STIC volume quality ${ }^{127}$; (2) a positive correlation exists between the "acquisition condition score" (score assigned to fetal movements, ROI setting, acquisition angle, cardiac apex position, and shadowing) and "quality" of STIC volumes ${ }^{36}$; specifically, the higher the acquisition condition score, the better the volume "quality" (based on the ability to display cardiac structures); and (3) in a multicenter study of 4D fetal echocardiography in the first trimester, centers that reviewed a higher (versus lower) percentage of suboptimal STIC volumes had lower accuracy for identifying $\mathrm{CHD}{ }^{22}$

Therefore, when STIC volume data sets are of high quality, they are more likely to be informative (ie, successful display of cardiac planes and anatomic structures) when analyzed. When the opposite is the case (ie, volume data sets of poor quality), the "garbage in, garbage out" principle used in the fields of computer science and information and communications technology applies. ${ }^{128}$ Specifically, computers (since they operate by logical processes) will unquestionably process unin- tended and even nonsensical input data (garbage in) to produce undesired and often nonsensical output (garbage out). ${ }^{128}$ Similarly, a STIC volume data set of suboptimal or poor quality will also produce undesired and uninformative "output." It follows, then, that improving the diagnosis of CHD based on STIC technology cannot occur if the quality of volume data sets is suboptimal or poor.

\section{Criteria for STIC Volume Acquisition}

When acquiring STIC volumes using prespecified criteria, the successful generation of information (eg, fetal cardiac views) should be more consistent among examinations than if no protocol were followed. For example, what would be the result if there were no STIC acquisition criteria pertaining to fetal spine location? It is likely that successful visualization of the 3-vessel and trachea view would be greater for a fetus with the spine located at 6 o'clock than at 12 o'clock (due to acoustic shadowing from the spine). Comparing and interpreting the performance of 4D sonography with STIC among studies may also be challenging, since it depends on whether acquisition criteria have been implemented. For example, one group of investigators may report that the rate of obtaining satisfactory fetal cardiac views using STIC technology is poor and therefore conclude that STIC should not be used in clinical practice. Another group might report exactly the opposite findings. However, for the first investigators, were STIC volumes obtained randomly, or were standardized criteria followed during the acquisition process? If the first scenario actually occurred (ie, STIC volumes obtained randomly), an unbeknownst reader will erroneously believe that $4 \mathrm{D}$ sonography with STIC has no clinical value. Taken together, if there is a lack of standardization in the acquisition of STIC volume data sets, it would be a major limiting step to effective performance of fetal cardiac examination using 4D sonography with STIC.

\section{Operator Training and Experience}

The acquisition of high-quality STIC volumes requires adequate training, and this factor is the key determinant of a successful complete cardiac examination. ${ }^{127}$ Moreover, investigators have reported the impact of experience, in which more experienced sonographers have: (1) a significantly higher success rate of STIC volume acquisition than those less experienced ( $88.4 \%$ versus $70.5 \%$; $P=.02)^{36}$; (2) significantly less reported fetal movements interfering with STIC volume acquisition (expert versus beginners, $12 \%$ versus $62 \% ; P<.05$ ); and (3) fewer 
motion artifacts observed in STIC volumes than in those acquired by beginners $(16 \%$ versus $42 \%$; $P<.05) .{ }^{36}$ Recently, Novaes et al ${ }^{129}$ reported that in normal fetuses, the proportion of STIC volumes considered adequate to demonstrate 5 cardiac views was higher for STIC "specialists" than "nonspecialists" (66.7\% versus $36.2 \%$; $P<$ .001 ). The latter group comprised physicians without experience in volumetric sonography.

Other factors besides operator skill and experience influence the quality of STIC volume data sets, such as fetal breathing and movements. ${ }^{32-34,130}$ It is noteworthy, however, that such factors also influence image quality in $2 \mathrm{D}$ sonography; therefore, these are not unique to 4D sonography with STIC. Indeed, it is important to clarify the relationship between these two sonographic modalities. A prevailing myth that should be abolished is that STIC technology is immune to some of the limitations inherent in $2 \mathrm{D}$ sonography. For example, we have been asked how to avoid acoustic shadows from being introduced into STIC volume data sets when the fetal spine is anteriorly located. STIC technology is just as susceptible to limitations in scanning windows ${ }^{36}$ as $2 \mathrm{D}$ sonography; thus, such issues cannot be resolved.

\section{What Is the Success Rate of STIC Volume Acquisition, and Are Such Volumes Informative?}

An important issue is the success rate of STIC volume acquisition when examining fetuses with normal hearts. These rates range widely from $26 \%$ to $100 \% 32,35,36,39,45,47-$ 49,77,84,85,92,114,115,129,131-134 (Table 2) and depend on many factors, such as operator training and skill, route of examination (transabdominal versus transvaginal), gestational age, maximum duration of the examination allowed, patient ambulation, and number of STIC volume acquisitions per patient. Yet, probably the most important factors influencing the volume acquisition rate are the preset criteria/requirements for acquisition, as well as their degree of rigor. ${ }^{92}$ These criteria may include specifics about fetal movement and breathing, fetal position, acoustic shadowing, and which anatomic structures should be visualized before volume acquisition begins. ${ }^{92}$ For example, at one end of the spectrum, if a transducer is simply placed over the fetal heart without any specifications, and the success rate of STIC acquisition is defined as just "obtaining a volume," the rate will be $100 \%$. In contrast, if there are stringent criteria required for obtaining a STIC volume data set, the success rate is likely to be lower.
The criteria set forth by investigators to acquire STIC volumes will vary, depending on the area(s) being studied. For example, if color Doppler velocimetry is combined with STIC to evaluate flow through the atrioventricular valves, it is acceptable for the fetal spine to be located anteriorly. When STIC M-mode is used to obtain fetal cardiac dimensions, ${ }^{57}$ assess ventricular fractional shortening, ${ }^{135}$ or measure ventricular wall and interventricular septal thickness, ${ }^{58}$ a lateral insonation of the fetal heart (ie, spine located laterally) is obtained (Figure 12 and Video 15). This situation is also the case when evaluating fetal pulmonary veins (STIC combined with B-flow) ${ }^{136}$ or the outflow tracts. ${ }^{37}$ However, when the goal is to assess fetal cardiac views, the spine should ideally be located posteriorly to minimize acoustic shadowing. ${ }^{116}$

Acquisition rates and/or the definition of an "acceptable" STIC volume data set are also influenced by the purpose of study (eg, to visualize cardiac views and structures or to calculate ventricular volumes and indices of cardiac function). For example, if the objective is to visualize the 4chamber view only, the rate of acceptable STIC volumes should be high. On the other hand, if clear demarcation of ventricular endocardial borders and absence of shadowing artifacts in multiple planes is required for evaluating fetal cardiac function, the rate of acceptable STIC volumes will be lower. ${ }^{84}$

Collectively, it is therefore important to keep these concepts in mind when reviewing reports on the success rates of STIC volume acquisition. In general, the greater the number and rigor of preset criteria/requirements, the lower the success rate will be. ${ }^{92} \mathrm{~A}$ far more crucial issue, however, is whether STIC volume data sets are informative (ie, ability to display cardiac planes and structures), which occurs only if they are of high quality. ${ }^{36}$ Just because a volume data set has been obtained, it does not necessarily translate into one that is clinically useful. Thus, there may not be a direct relationship between the STIC acquisition rate and the quality of information that can be derived from such volumes. For example, the acquisition rate may be $100 \%$, but due to suboptimal STIC quality, volumes may be uninformative. The flip side is that stringent acquisition criteria may lead to lower STIC volume acquisition rates, but volumes may be very informative.

In some cases, acquisition of an appropriate STIC volume will not be possible despite multiple attempts (eg, secondary to an uncooperative fetus or maternal obesity). Yet, these factors are no different from those of conventional 2D sonography, in which a successful fetal cardiac examination may not always be possible. 

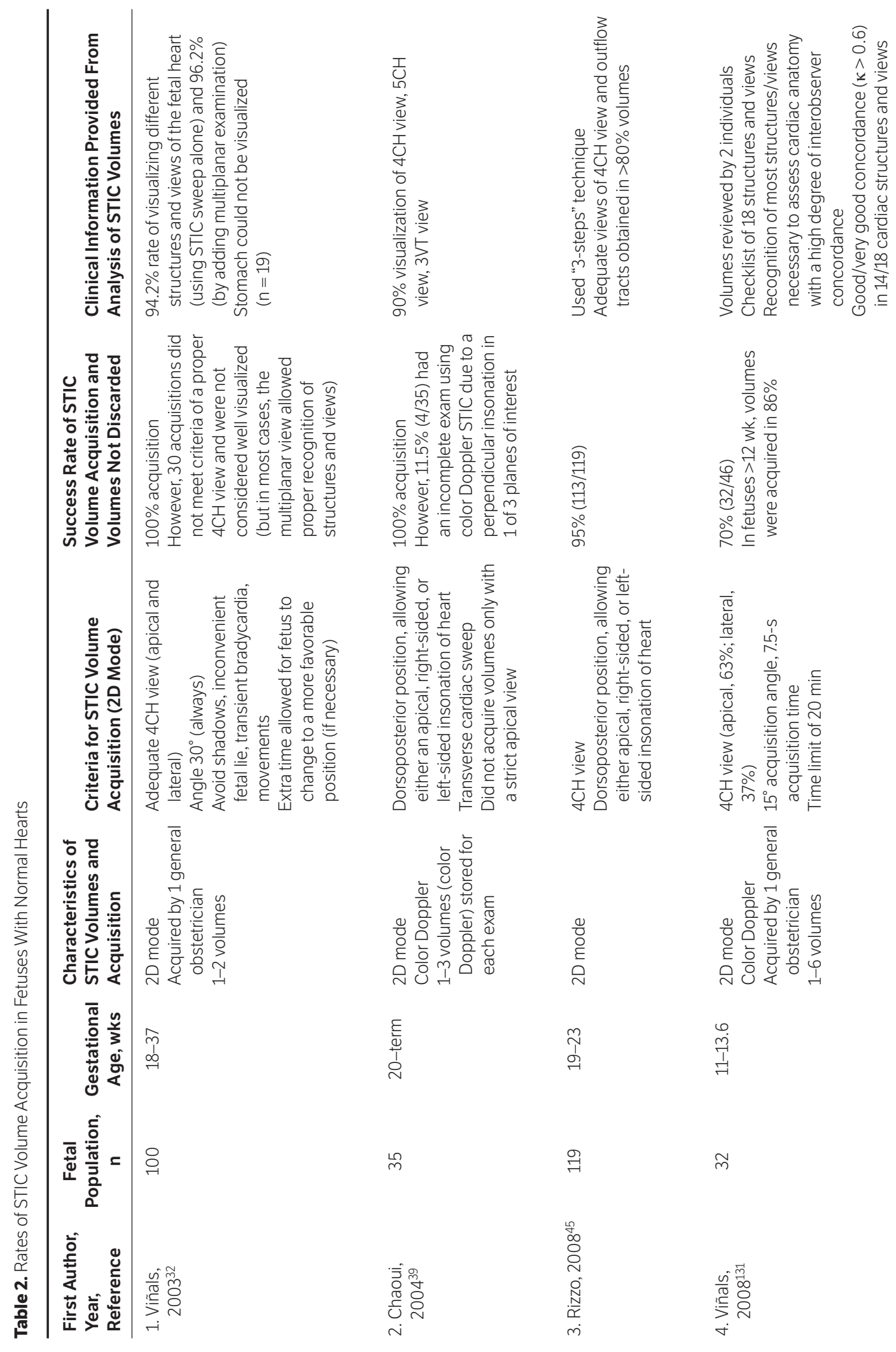

$\frac{E}{2}$
$\frac{1}{1}$
$\stackrel{2}{N}$

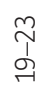

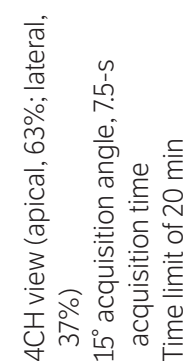

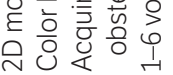

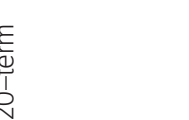

$\stackrel{\llcorner}{m}$

극

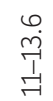

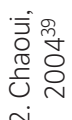

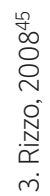



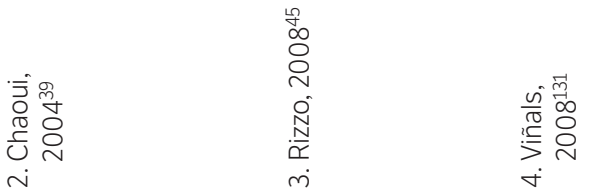




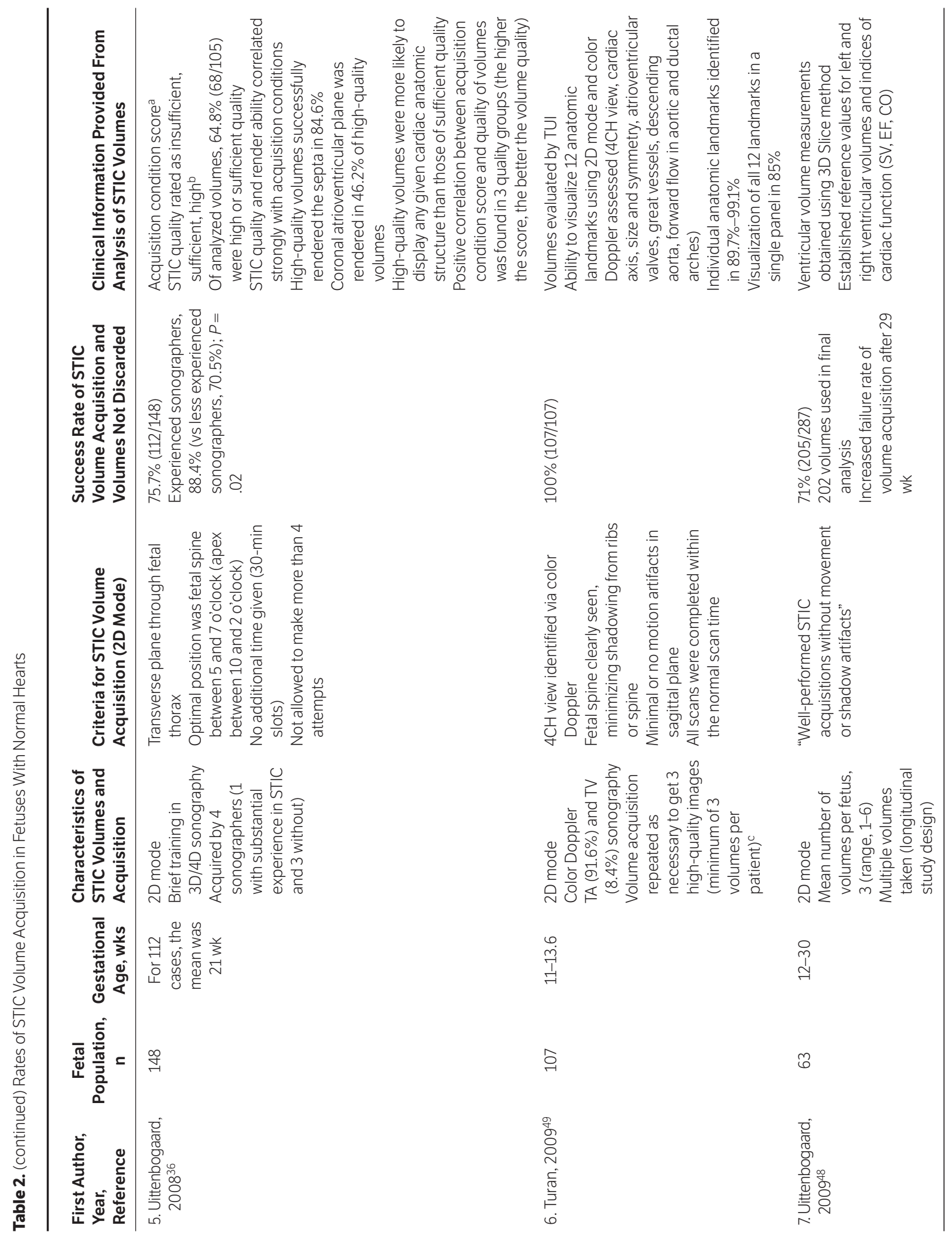




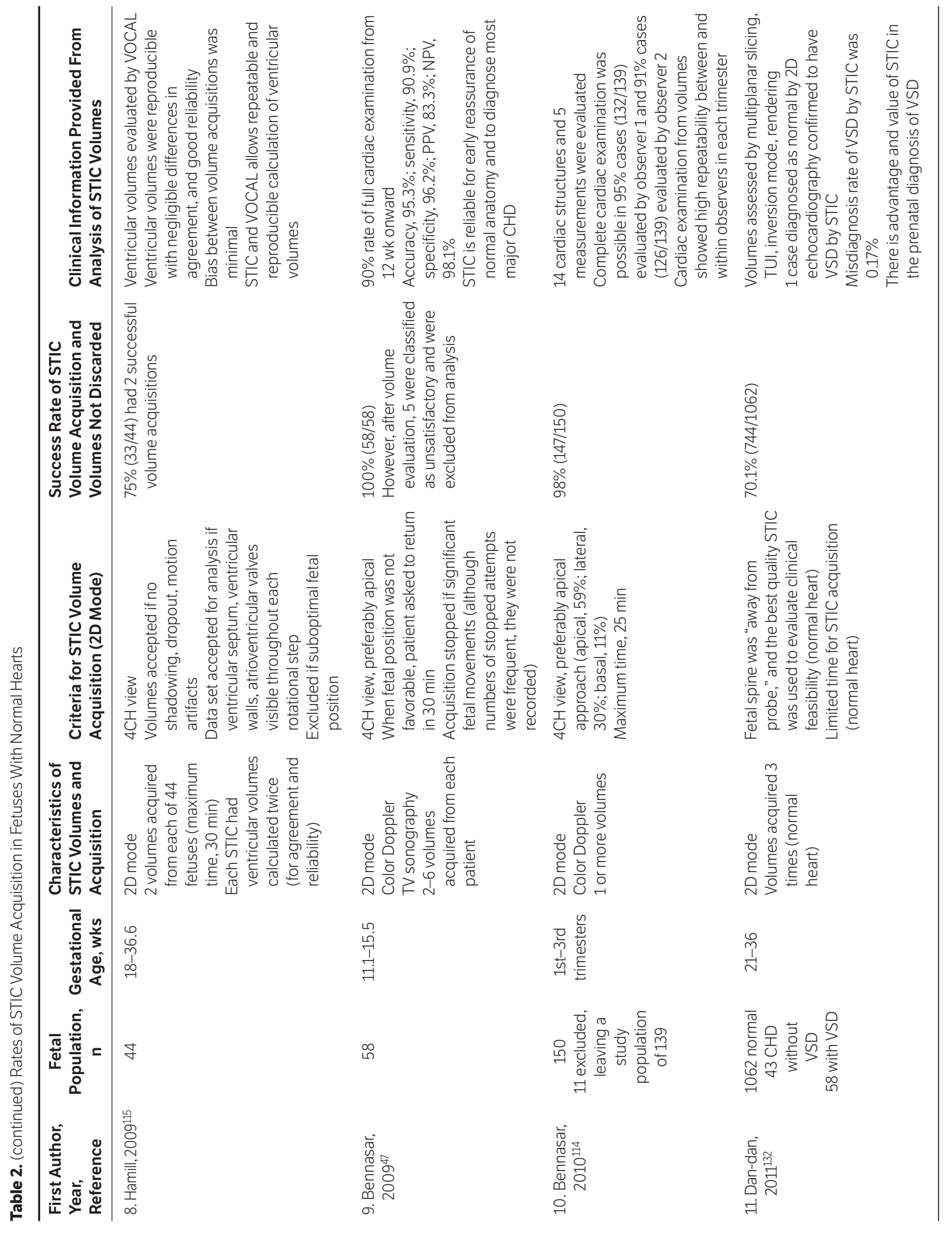




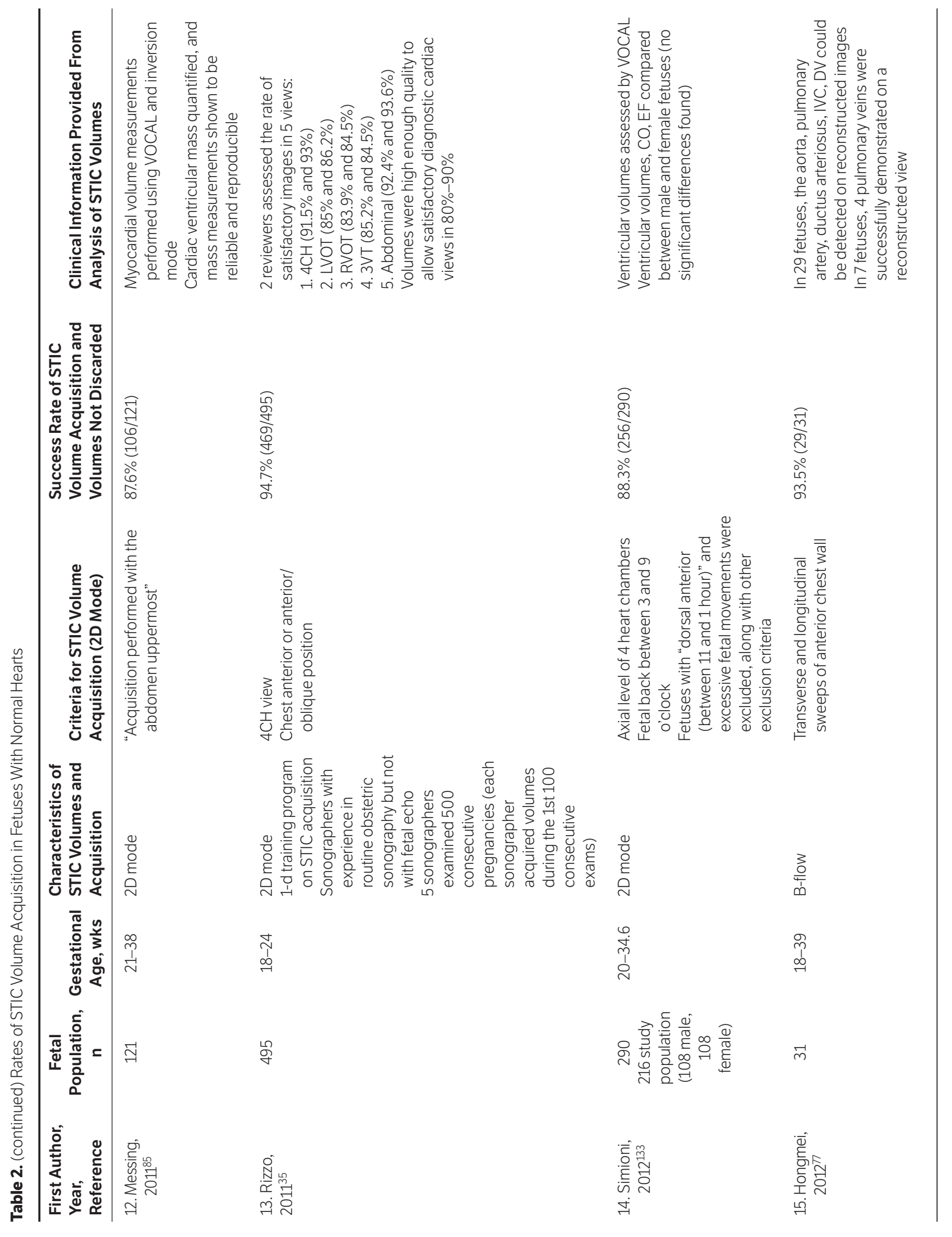




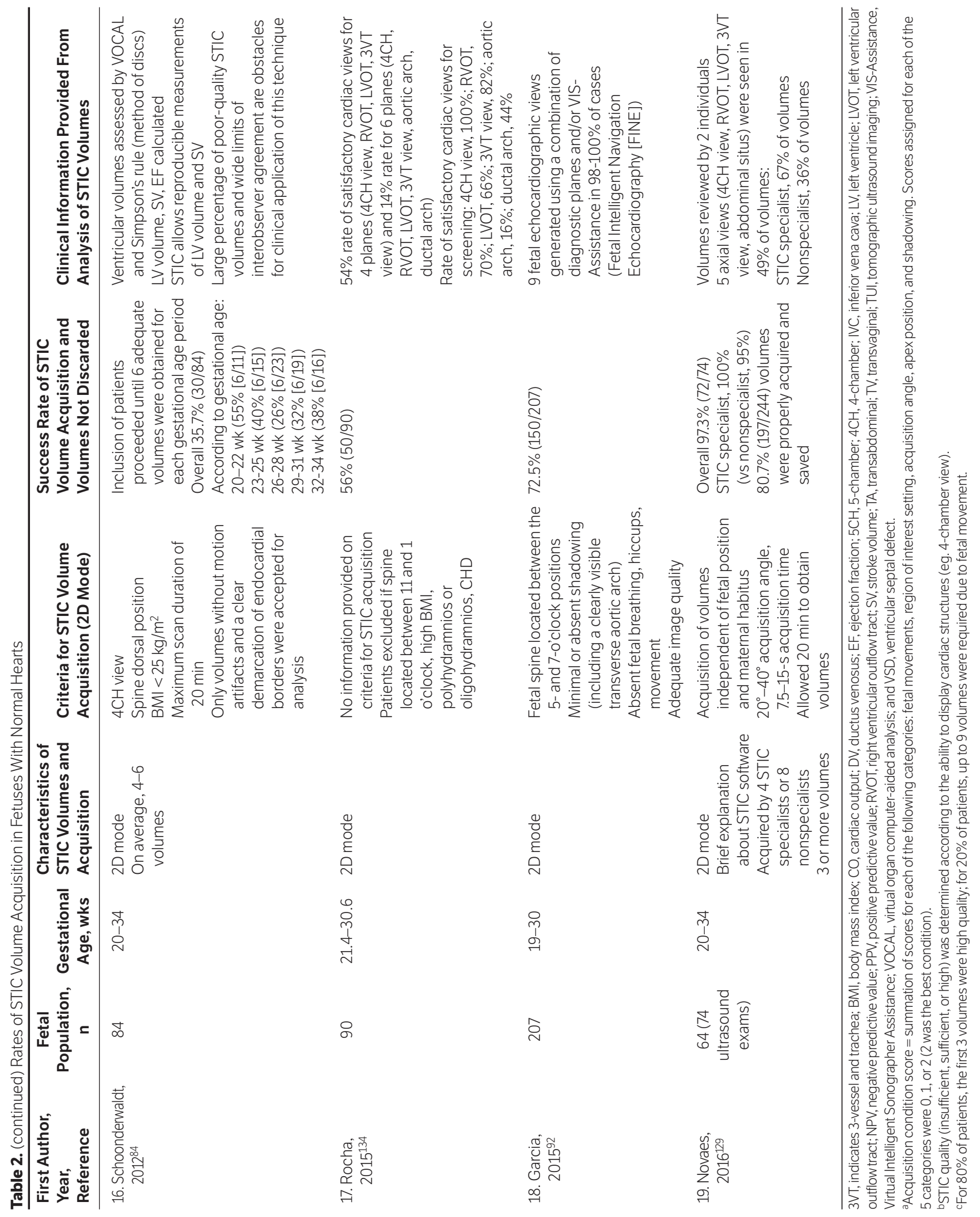




\section{How to Perform 4D Sonography With STIC}

There are 4 essential steps when performing 4D sonography with STIC: (1) volume acquisition; (2) volume display; (3) volume manipulation/postprocessing; and (4) storage of volumes and images. After STIC volume acquisition, standardization of the multiplanar view, volume interrogation to obtain cardiac views and/or rendering of the volume is performed. In this article, we will review concepts pertaining to STIC volume acquisition and display only.

Three main time points deserve focus when acquiring STIC volume data sets and determining their appropriateness for analysis: (1) before acquisition of STIC volumes; (2) acquisition of STIC volumes; and (3) immediately after acquisition of STIC volumes (ie, multiplanar display and/or STICLoop ${ }^{90}$ ).

It is noteworthy that the specific approach described herein pertains to STIC volumes acquired through a transabdominal approach, using B-mode sonography, and via a transverse acquisition plane of the fetal chest (level of the 4-chamber view). We recognize that not every aspect of this approach will apply to all clinical situations and will vary depending on the primary goal. Our intent is to describe an overall practical method to serve as a guide. Moreover, if the described technique is not followed, it does not necessarily mean that the STIC volume data set will be uninformative. Indeed, clinically useful information can still be obtained from STIC volumes derived by using a variety of approaches, provided that they are of high quality.

At what gestational ages should STIC volumes be obtained? In general, we recommend that volumes be acquired between 19 and 30 weeks' gestation for optimal assessment of fetal cardiac anatomy ${ }^{92}$ High-quality STIC volumes tend to become more difficult to acquire after this gestational age range, due to fetal positioning and acoustic shadowing. Indeed, authors have reported that only a few high-quality STIC volumes can be acquired beyond 29 weeks' gestation. ${ }^{48}$ It is noteworthy, however, that volumes of superior quality can still be obtained throughout the third trimester, even up to 39 weeks' gestation. ${ }^{90}$ Moreover, in the first and early second trimesters, a detailed evaluation of both normal and abnormal fetal hearts using STIC technology can be performed. ${ }^{22,47,49,127,131,137}$ This fact is clinically relevant, due to the increasing role of first-trimester fetal cardiac examination ${ }^{138-143}$ (eg, increased nuchal translucency thickness in the presence of a normal fetal karyotype). However, the challenges of performing 4D sonography with STIC in the first trimester include frequent fetal motion and the size of cardiac structures. Transvaginal sonography may be used to obtain volumes in early pregnancy. ${ }^{22,47,49,127}$

\section{General Recommendations}

We propose the following general recommendations when performing 4D sonography with STIC:

1. Play an Active Role-If possible, sonologists should proactively get the fetus into a more optimal position and/or move fetal parts out of the imaging field of view. For example, the following actions can be performed: (1) Ask the mother who is lying supine to turn (or roll) laterally onto her side in the same direction that you wish the fetal cardiac apex to turn. For example, let us assume that a vertex fetus has the cardiac apex located at 7 o'clock (transverse plane of the chest) on the monitor screen. If the desired effect is movement of the fetal cardiac apex to an 11-o'clock position (a "clockwise roll"), the mother also should be asked to roll in a clockwise direction, so that she comes to rest on her left side. In our experience, frequently changing the maternal position (eg, rolling to either or both lateral sides, ambulating, going to the restroom, or sitting up) will usually change the fetal position successfully into the desired one. (2) Gently "move" the fetus into the desired position by placing one's hands on the maternal abdomen. (3) Gently tap on the maternal abdomen or ask the mother to cough, so that fetal parts (eg, an extremity) move out of the field of view. (4) Change the tilt and position of the examination bed. Understandably, women often prefer the upper part of the bed to be raised at an angle for comfort. However, when the entire bed is tilted upward (head higher than the feet), or the bed is "jackknifed" or bent at the midway point of the bed (and, thus, the maternal waist), maneuvering the probe around the maternal abdomen is sometimes suboptimal and awkward because sonologists may have to bend their wrists backward to obtain optimal images. Therefore, when possible, we prefer to scan patients lying completely supine to "flatten" their abdomen or with the entire bed tilted downward (feet higher than the head). In our experience, this position allows easier maneuvering and tilting of the transducer, and sonologists are able to bend their wrist forward to scan.

2. Practice Efficiency During the Sonographic Examination-Success in STIC volume acquisition can be achieved by constantly adapting to the fetal situation. Using this approach is particularly relevant when imaging the fetal heart, since examination of this organ is highly dependent on fetal position, and fetuses can move frequently. A few examples of practicing efficiency during the sonographic examination include 
the following: (1) Recognize when there is an optimal moment to image the fetal heart and acquire STIC volume data sets. If the fetal spine is anteriorly located at first, but the fetus suddenly flips to a supine position, one should immediately focus on cardiac examination. If the fetal heart is already in an optimal position, and conditions are appropriate (eg, absence of fetal breathing or movement), the sonologist should take advantage of this opportunity by immediately acquiring multiple STIC volumes in rapid succession. Such a chance may not occur again. (2) In the presence of a suboptimal fetal position, instead of trying repeatedly and unsuccessfully to image cardiac structures, one can examine other fetal organs, obtain biometric measurements, etc, to allow time for the fetus to change into a more optimal position. While doing so, the sonologist should frequently check back to see whether the fetal heart can now be imaged successfully using STIC. Thus, in summary, one should always be "on the lookout" throughout the sonographic examination and take advantage of any proper moments to obtain STIC volumes.

3. Use a Volumetric Transducer Throughout the Examination-If the sonologist plans to acquire STIC volume data sets during the sonographic examination, it is advantageous to use a volumetric transducer throughout the study. This use avoids having to switch back and forth between a probe used for $2 \mathrm{D}$ imaging and a volumetric transducer, all of which takes time, requires setting changes, and is inefficient when practiced frequently. Fortunately, next-generation volume transducers have been designed to be lighter than previous versions, for the purpose of reducing user fatigue.

4. Prepare the Machine Settings Beforehand-Since capturing STIC volume data sets can occur at any time during the examination, it is helpful to "prepare" the acquisition settings on the ultrasound machine beforehand (eg, adjust the ROI size, decrease the depth, and set the acquisition angle and time). Such measures are helpful because if conditions suddenly become optimal for STIC acquisition (eg, fetal spine moves to a 6-o'clock position), the settings have already been programmed, and one can immediately proceed with the acquisition. If this preparation has not occurred beforehand, sometimes while the operator spends time adjusting the settings, fetuses will change position or commence breathing movements, and the chance becomes lost. Of course, despite all preparations, adjustments are sometimes necessary (eg, change the depth) due to a dynamic fetal environment.
5. Prepare the Patient Beforehand - It is helpful to explain to patients ahead of time that there may be attempt(s) throughout the sonographic examination to obtain STIC volumes; therefore, her participation is encouraged (eg, maintain a breath hold and remain motionless). The purpose of 4D sonography with STIC and how it is performed should be discussed with the patient. In general, we have found such a practice to be invaluable because patients are informed, prepared ahead of time, and more likely to be cooperative.

\section{Conclusions}

Prenatal diagnosis of CHD is important, since it is the leading organ-specific birth defect and the leading cause of infant morbidity and mortality from congenital malformations. However, sonographic evaluation of the fetal heart is one of the most difficult tasks in prenatal diagnosis, and the detection of CHD remains challenging. Since STIC technology was first described 13 years ago, a large body of evidence suggests that it facilitates examination of the fetal heart and has the potential to reduce the operator dependency associated with conventional 2D sonography. Four-dimensional sonography with STIC has also been used to successfully evaluate and diagnose $\mathrm{CHD}$, as well as assess fetal cardiac function. Yet, despite the advantages of 4D sonography with STIC over conventional 2D sonography, the former has been underused and its value underestimated.

STIC volume acquisition can be incorporated into the daily practice of ultrasound centers. However, using such technology to examine the fetal heart requires an important prerequisite: the training of sonologists to acquire high-quality volume data sets so that they are informative. Here we have described general recommendations on the performance of 4D sonography with STIC. In part 2 of this article, ${ }^{96}$ we discuss a detailed and practical stepwise approach for STIC volume acquisition, along with methods to determine whether such volumes are appropriate for analysis.

Our overall goal is to demystify an imaging modality that is considered by many to be too complicated and challenging to perform. By doing so, the objective is to encourage sonologists to embrace STIC technology as an additional and valuable tool for examining the fetal heart. Since the sensitivity of $2 \mathrm{D}$ sonography for $\mathrm{CHD}$ has not improved over the last decade, ${ }^{20}$ there is a need to address this long-standing problem and offer a solution that could improve detection rates. Bringing high-quality ultrasound screening to all pregnant women is essential, and 4D sonography with STIC should move to the forefront of this solution. In doing so, the first steps include education and training each other. 


\section{References}

1. Centers for Disease Control and Prevention (CDC). Improved national prevalence estimates for 18 selected major birth defects - United States, 1999-2001. MMWR Morb Mortal Wkly Rep 2006; 54:1301-1305.

2. Yang Q, Chen H, Correa A, Devine O, Mathews TJ, Honein MA. Racial differences in infant mortality attributable to birth defects in the United States, 1989-2002. Birth Defects Res A Clin Mol Teratol 2006; 76:706713.

3. SchultzAH, Localio AR, Clark BJ, Ravishankar C, Videon N, Kimmel SE. Epidemiologic features of the presentation of critical congenital heart disease: implications for screening. Pediatrics 2008; 121:751-757.

4. Brown KL, Ridout DA, Hoskote A, Verhulst L, Ricci M, Bull C. Delayed diagnosis of congenital heart disease worsens preoperative condition and outcome of surgery in neonates. Heart 2006; 92:1298-1302.

5. Tworetzky W, McElhinney DB, Reddy VM, Brook MM, Hanley FL, Silverman NH. Improved surgical outcome after fetal diagnosis of hypoplastic left heart syndrome. Circulation 2001; 103:1269-1273.

6. Verheijen PM, Lisowski LA, Stoutenbeek P, Hitchcock JF, Bennink GB, Meijboom EJ.Lactacidosis in the neonate is minimized by prenatal detection of congenital heart disease. Ultrasound Obstet Gynecol 2002; 19:552555.

7. Kumar RK, Newburger JW, Gauvreau K, Kamenir SA, Hornberger LK. Comparison of outcome when hypoplastic left heart syndrome and transposition of the great arteries are diagnosed prenatally versus when diagnosis of these two conditions is made only postnatally. Am J Cardiol 1999; 83:1649-1653.

8. van Velzen CL, Haak MC, Reijnders G, et al. Prenatal detection of transposition of the great arteries reduces mortality and morbidity. Ultrasound Obstet Gynecol 2015; 45:320-325.

9. Franklin O, Burch M, Manning N, Sleeman K, Gould S, Archer N. Prenatal diagnosis of coarctation of the aorta improves survival and reduces morbidity. Heart 2002; 87:67-69.

10. Gómez-Montes E, Herraiz I, Mendoza A, Escribano D, Galindo A. Prediction of coarctation of the aorta in the second half of pregnancy. Ultrasound Obstet Gynecol 2013; 41:298-305.

11. Bonnet D, Coltri A, Butera G, et al. Detection of transposition of the great arteries in fetuses reduces neonatal morbidity and mortality. Circulation 1999; 99:916-918.

12. Khoshnood B, De Vigan C, Vodovar V, et al. Trends in prenatal diagnosis, pregnancy termination, and perinatal mortality of newborns with congenital heart disease in France, 1983-2000: a population-based evaluation. Pediatrics 2005; 115:95-101.

13. Mahle WT, Clancy RR, McGaurn SP, Goin JE, Clark BJ. Impact of prenatal diagnosis on survival and early neurologic morbidity in neonates with the hypoplastic left heart syndrome. Pediatrics 2001; 107:1277-1282.

14. Kipps AK, Feuille C, Azakie A, et al. Prenatal diagnosis of hypoplastic left heart syndrome in current era. Am J Cardiol 201 1; 108:421-427.

15. Poole PS, Chung R, Lacoursiere Y, et al. Two-dimensional sonographic cine imaging improves confidence in the initial evaluation of the fetal heart. JUltrasound Med 2013; 32:963-971.
16. Ganesan S, Brook MM, Silverman NH, Moon-Grady AJ. Prenatal findings in total anomalous pulmonary venous return: a diagnostic road map starts with obstetric screening views. J Ultrasound Med 2014; 33:1 193 1207.

17. Chew C, Halliday JL, Riley MM, Penny DJ. Population-based study of antenatal detection of congenital heart disease by ultrasound examination. Ultrasound Obstet Gynecol 2007; 29:619-624.

18. Khoo NS, Van Essen P, Richardson M, Robertson T. Effectiveness of prenatal diagnosis of congenital heart defects in South Australia: a population analysis 1999-2003. Aust NZ J Obstet Gynaecol 2008; 48:559-563.

19. Friedberg MK, Silverman NH, Moon-Grady AJ, et al. Prenatal detection of congenital heart disease.J Pediatr 2009; 155:26-31.

20. Pinto NM, Keenan HT, Minich LL, Puchalski MD, Heywood M, Botto LD. Barriers to prenatal detection of congenital heart disease: a population-based study. Ultrasound Obstet Gynecol 2012; 40:418-425.

21. Wu LH, Wang N, Xie HN, Du L, Peng R. Cardiovascular Z-scores in fetuses with tetralogy of Fallot. Ultrasound Obstet Gynecol 2014; 44:674681.

22. Espinoza J, Lee W, Viñals F, et al. Collaborative study of 4-dimensional fetal echocardiography in the first trimester of pregnancy.J Ultrasound Med 2014; 33:1079-1084.

23. International Society of Ultrasound in Obstetrics and Gynecology, Carvalho JS, Allan LD, Chaoui R, et al. ISUOG Practice Guidelines (updated): sonographic screening examination of the fetal heart. Ultrasound Obstet Gynecol 2013; 41:348-359.

24. Allan L, Benacerraf B, Copel JA, et al. Isolated major congenital heart disease. Ultrasound Obstet Gynecol 2001; 17:370-379.

25. Carvalho JS, Mavrides E, Shinebourne EA, Campbell S, Thilaganathan B. Improving the effectiveness of routine prenatal screening for major congenital heart defects. Heart 2002; 88:387-391.

26. Hunter S, Heads A, Wyllie J, Robson S. Prenatal diagnosis of congenital heart disease in the northern region of England: benefits of a training programme for obstetric ultrasonographers. Heart 2000; 84:294-298.

27. Rustico MA, Benettoni A, D'Ottavio G, et al. Early screening for fetal cardiac anomalies by transvaginal echocardiography in an unselected population: the role of operator experience. Ultrasound Obstet Gynecol 2000; 16:614-619.

28. Tegnander E, Eik-Nes SH. The examiner's ultrasound experience has a significant impact on the detection rate of congenital heart defects at the second-trimester fetal examination. Ultrasound Obstet Gynecol 2006; 28:814.

29. Wong SF, Chan FY, Cincotta RB, Lee-TannockA, Ward C. Factors influencing the prenatal detection of structural congenital heart diseases. Ultrasound Obstet Gynecol 2003; 21:19-25.

30. Baardman ME, du Marchie Sarvaas GJ, de Walle HE, et al. Impact of introduction of 20-week ultrasound scan on prevalence and fetal and neonatal outcomes in cases of selected severe congenital heart defects in the Netherlands. Ultrasound Obstet Gynecol 2014; 44:58-63.

31. Tutschek B, Sahn DJ. Three-dimensional echocardiography for studies of the fetal heart: present status and future perspectives. Cardiol Clin 2007; 25:341-355. 
32. Viñals F, Poblete P, Giuliano A. Spatio-temporal image correlation (STIC): a new tool for the prenatal screening of congenital heart defects. Ultrasound Obstet Gynecol 2003; 22:388-394.

33. DeVore GR, Falkensammer P, Sklansky MS, Platt LD. Spatiotemporal image correlation (STIC): new technology for evaluation of the fetal heart. Ultrasound Obstet Gynecol 2003; 22:380-387.

34. Gonçalves LF, Lee W, Chaiworapongsa T, et al. Four-dimensional ultrasonography of the fetal heart with spatiotemporal image correlation. Am J Obstet Gynecol 2003; 189:1792-1802.

35. Rizzo G, Capponi A, Pietrolucci ME, et al. Satisfactory rate of postprocessing visualization of standard fetal cardiac views from 4-dimensional cardiac volumes acquired during routine ultrasound practice by experienced sonographers in peripheral centers. JUltrasound Med 2011;30:9399.

36. Uittenbogaard LB, Haak MC, Spreeuwenberg MD, Van VugtJM. A systematic analysis of the feasibility of four-dimensional ultrasound imaging using spatiotemporal image correlation in routine fetal echocardiography. Ultrasound Obstet Gynecol 2008; 31:625-632.

37. DeVore GR, Polanco B, Sklansky MS, Platt LD. The "spin" technique: a new method for examination of the fetal outflow tracts using three-dimensional ultrasound. Ultrasound Obstet Gynecol 2004; 24:72-82.

38. Espinoza J, Gonçalves LF, Lee W, et al. The use of the minimum projection mode in 4-dimensional examination of the fetal heart with spatiotemporal image correlation. J Ultrasound Med 2004; 23:1337-1348.

39. Chaoui R, Hoffmann J, Heling KS. Three-dimensional (3D) and 4D color Doppler fetal echocardiography using spatio-temporal image correlation (STIC). Ultrasound Obstet Gynecol 2004; 23:535-545.

40. Gonçalves LF, Romero R, Espinoza J, et al. Four-dimensional ultrasonography of the fetal heart using color Doppler spatiotemporal image correlation. JUltrasound Med 2004; 23:473-481.

41. Chaoui R, Heling KS. New developments in fetal heart scanning: threeand four-dimensional fetal echocardiography. Semin Fetal Neonatal Med 2005; 10:567-577.

42. Espinoza J, Kusanovic JP, Gonçalves LF, et al. A novel algorithm for comprehensive fetal echocardiography using 4-dimensional ultrasonography and tomographic imaging. J Ultrasound Med 2006; 25:947956.

43. Yagel S, Cohen SM, Shapiro I, Valsky DV.3D and 4D ultrasound in fetal cardiac scanning: a new look at the fetal heart. Ultrasound Obstet Gynecol 2007; 29:81-95.

44. Molina FS, Faro C, Sotiriadis A, Dagklis T, Nicolaides KH. Heart stroke volume and cardiac output by four-dimensional ultrasound in normal fetuses. Ultrasound Obstet Gynecol 2008; 32:181-187.

45. Rizzo G, Capponi A, Muscatello A, Cavicchioni O, Vendola M, Arduini $D$. Examination of the fetal heart by four-dimensional ultrasound with spatiotemporal image correlation during routine second-trimester examination: the "three-steps technique." Fetal Diagn Ther 2008; 24:126-131.

46. Tutschek B, Sahn DJ. Semi-automatic segmentation of fetal cardiac cavities: progress towards an automated fetal echocardiogram. Ultrasound Obstet Gynecol 2008; 32:176-180.
47. Bennasar M, Martínez JM, Olivella A, et al. Feasibility and accuracy of fetal echocardiography using four-dimensional spatiotemporal image correlation technology before 16 weeks' gestation. Ultrasound Obstet Gynecol 2009; 33:645-651.

48. Uittenbogaard LB, Haak MC, Spreeuwenberg MD, van Vugt JM. Fetal cardiac function assessed with four-dimensional ultrasound imaging using spatiotemporal image correlation. Ultrasound Obstet Gynecol 2009; 33:272-281.

49. Turan S, Turan OM, Ty-Torredes K, Harman CR, Baschat AA. Standardization of the first-trimester fetal cardiac examination using spatiotemporal image correlation with tomographic ultrasound and color Doppler imaging. Ultrasound Obstet Gynecol 2009; 33:652-656.

50. Gonçalves LF, Espinoza J, Romero R, et al. Four-dimensional ultrasonography of the fetal heart using a novel Tomographic Ultrasound Imaging display. J Perinat Med 2006; 34:39-55.

51. Cohen L, Mangers K, Grobman WA, Platt LD. Satisfactory visualization rates of standard cardiac views at 18 to 22 weeks' gestation using spatiotemporal image correlation. J Ultrasound Med 2009; 28:1645-1650.

52. Abuhamad A, Chaoui R (eds).A Practical Guide to Fetal Echocardiography: Normal and Abnormal Hearts. Philadelphia, PA: Lippincott Williams \& Wilkins; 2010.

53. Rizzo G, Capponi A, Pietrolucci ME, Arduini D. Role of sonographic automatic volume calculation in measuring fetal cardiac ventricular volumes using 4-dimensional sonography: comparison with virtual organ computer-aided analysis. J Ultrasound Med 2010; 29:261-270.

54. Jantarasaengaram S, Vairojanavong K. Eleven fetal echocardiographic planes using 4-dimensional ultrasound with spatio-temporal image correlation (STIC): a logical approach to fetal heart volume analysis. Cardiovasc Ultrasound 2010; 8:41.

55. Yeo L, Romero R,Jodicke C, etal.Four-chamberview and "swing technique" (FAST) echo: a novel and simple algorithm to visualize standard fetal echocardiographic planes. Ultrasound Obstet Gynecol 201 1; 37:423-431.

56. Hamill N, Yeo L, Romero R, et al. Fetal cardiac ventricular volume, cardiac output, and ejection fraction determined with 4-dimensional ultrasound using spatiotemporal image correlation and virtual organ computer-aided analysis. Am J Obstet Gynecol 2011; 205:76.e1-76.e10.

57. Luewan S, Yanase Y, Tongprasert F, Srisupundit K, Tongsong T. Fetal cardiac dimensions at 14-40 weeks' gestation obtained using cardioSTIC-M. Ultrasound Obstet Gynecol 2011; 37:416-422.

58. Wang N, Xie HN, Peng R, Zheng J, Zhu YX. Accuracy, agreement, and reliability of fetal cardiac measurements using 4-dimensional spatiotemporal image correlation. JUltrasound Med 2012; 31:1719-1726.

59. Messing B, Gilboa Y, Lipschuetz M, Valsky DV, Cohen SM, Yagel S. Fetal tricuspid annular plane systolic excursion (f-TAPSE): evaluation of fetal right heart systolic function with conventional M-mode ultrasound and spatiotemporal image correlation (STIC) M-mode. Ultrasound Obstet Gynecol 2013; 42:182-188.

60. Tudorache S, Cara M, Iliescu DG, Novac L, Cernea N. First trimester two- and four-dimensional cardiac scan: intra- and interobserver agreement, comparison between methods and benefits of color Doppler technique. Ultrasound Obstet Gynecol 2013; 42:659-668. 
61. Yeo L, Romero R, Jodicke C, et al. Simple targeted arterial rendering (STAR) technique: a novel and simple method to visualize the fetal cardiac outflow tracts. Ultrasound Obstet Gynecol 201 1; 37:549-556.

62. Espinoza J. Contemporary clinical applications of spatio-temporal image correlation in prenatal diagnosis. Curr Opin Obstet Gynecol 2011; 23:94102.

63. Espinoza J, Lee W, Comstock C, et al. Collaborative study on 4-dimensional echocardiography for the diagnosis of fetal heart defects: the COFEHD study. J Ultrasound Med 2010; 29:1573-1580.

64. Bennasar M, MartínezJM, Gómez O, et al. Accuracy of four-dimensional spatiotemporal image correlation echocardiography in the prenatal diagnosis of congenital heart defects. Ultrasound Obstet Gynecol 2010; 36:458464 .

65. Gonçalves LF, Espinoza J, Lee W, Mazor M, Romero R. Three-and fourdimensional reconstruction of the aortic and ductal arches using inversion mode: a new rendering algorithm for visualization of fluid-filled anatomical structures. Ultrasound Obstet Gynecol 2004; 24:696-698.

66. Gonçalves LF, Espinoza J, Romero R, et al. A systematic approach to prenatal diagnosis of transposition of the great arteries using 4-dimensional ultrasonography with spatiotemporal image correlation. J Ultrasound Med 2004; 23:1225-1231.

67. Gonçalves LF, Espinoza J, Lee W, et al. A new approach to fetal echocardiography: digital casts of the fetal cardiac chambers and great vessels for detection of congenital heart disease. J Ultrasound Med 2005; 24:415424.

68. Viñals F, Mandujano L, Vargas G, Giuliano A. Prenatal diagnosis of congenital heart disease using four-dimensional spatio-temporal image correlation (STIC) telemedicine via an Internet link: a pilot study. Ultrasound Obstet Gynecol 2005; 25:25-31.

69. Ghi T, Cera E, Segata M, Michelacci L, Pilu G, Pelusi G. Inversion mode spatio-temporal image correlation (STIC) echocardiography in threedimensional rendering of fetal ventricular septal defects. Ultrasound Obstet Gynecol 2005; 26:679-680.

70. Paladini D, Sglavo G, Greco E, Nappi C. Cardiac screening by STIC: can sonologists performing the 20-week anomaly scan pick up outflow tract abnormalities by scrolling the A-plane of STIC volumes? Ultrasound Obstet Gynecol 2008; 32:865-870.

71. Gindes L, Hegesh J,Weisz B, Gilboa Y,Achiron R. Three and four dimensional ultrasound: a novel method for evaluating fetal cardiac anomalies. Prenat Diagn 2009; 29:645-653.

72. Hata T, Mashima M, Ito M, Uketa E, Mori N, Ishimura M. Three-dimensional HDlive rendering images of the fetal heart. Ultrasound Med Biol 2013; 39:1513-1517.

73. Xiong Y, Liu T, Wu Y, et al. Comparison of real-time three-dimensional echocardiography and spatiotemporal image correlation in assessment of fetal interventricular septum. J Matern Fetal Neonatal Med 2012; 25:2333-2338.

74. Zhang M, Pu DR, Zhou QC, Peng QH, Tian LQ. Four-dimensional echocardiography with B-flow imaging and spatiotemporal image correlation in the assessment of congenital heart defects. Prenat Diagn 2010; 30:443-448.
75. Hata T, Tanaka H, NoguchiJ, Dai SY, Yamaguchi M, Yanagihara T. Fourdimensional volume-rendered imaging of the fetal ventricular outflow tracts and great arteries using inversion mode for detection of congenital heart disease. J Obstet Gynaecol Res 2010; 36:513-518.

76. Adriaanse BM, Tromp CH, Simpson JM, et al. Interobserver agreement in detailed prenatal diagnosis of congenital heart disease by telemedicine using four-dimensional ultrasound with spatiotemporal image correlation. Ultrasound Obstet Gynecol 2012; 39:203-209.

77. Hongmei W, Ying Z, Ailu C, Wei S. Novel application of four-dimensional sonography with B-flow imaging and spatiotemporal image correlation in the assessment of fetal congenital heart defects. Echocardiography 2012; 29:614-619.

78. He Y, Wang J, Gu X, et al. Application of spatio-temporal image correlation technology in the diagnosis of fetal cardiac abnormalities. Exp Ther $\operatorname{Med} 2013 ; 5: 1637-1642$.

79. Qin Y,Zhang Y,Zhou X, et al. Four-dimensional echocardiography with spatiotemporal image correlation and inversion mode for detection of congenital heart disease. Ultrasound Med Biol 2014; 40:1434-1441.

80. Volpe P, Tuo G, De Robertis V, et al. Fetal interrupted aortic arch: 2D-4D echocardiography, associations and outcome. Ultrasound Obstet Gynecol 2010; 35:302-309.

81. Myers SA, Fresquez M, Hamill N. Four-dimensional sonography of the fetal heart with spatiotemporal image correlation directed at the interventricular septum. J Ultrasound Med 2007; 26:1071-1075.

82. Messing B, Cohen SM, Valsky DV, et al. Fetal cardiac ventricle volumetry in the second half of gestation assessed by 4D ultrasound using STIC combined with inversion mode. Ultrasound Obstet Gynecol 2007; 30:142-151.

83. Rizzo G, Capponi A, Cavicchioni O, Vendola M, Arduini D. Fetal cardiac stroke volume determination by four-dimensional ultrasound with spatio-temporal image correlation compared with two-dimensional and Doppler ultrasonography. Prenat Diagn 2007; 27:1147-1150.

84. Schoonderwaldt EM, Groenenberg IA, Hop WC, Wladimiroff JW, Steegers EA. Reproducibility of echocardiographic measurements of human fetal left ventricular volumes and ejection fractions using fourdimensional ultrasound with the spatio-temporal image correlation modality. Eur J Obstet Gynecol Reprod Biol 2012; 160:22-29.

85. Messing B, Cohen SM, Valsky DV, et al. Fetal heart ventricular mass obtained by STIC acquisition combined with inversion mode and VOCAL. Ultrasound Obstet Gynecol 2011; 38:191-197.

86. Simioni C, Nardozza LM, Araujo Júnior E, et al. Heart stroke volume, cardiac output, and ejection fraction in 265 normal fetus in the second half of gestation assessed by 4D ultrasound using spatio-temporal image correlation. J Matern Fetal Neonatal Med 201 1;24:1159-1167.

87. Uittenbogaard LB, Haak MC, Tromp CH, Terwee CB, Van Vugt JM. Reliability of fetal cardiac volumetry using spatiotemporal image correlation: assessment of in-vivo and in-vitro measurements. Ultrasound Obstet Gynecol 2010; 36:308-314.

88. Hamill N, Romero R, Hassan S, et al. The fetal cardiovascular response to increased placental vascular impedance to flow determined with 4-dimensional ultrasound using spatiotemporal image correlation and virtual organ computer-aided analysis. Am J Obstet Gynecol 2013; 208:153.el-153.e13. 
89. Abuhamad A, Falkensammer P, Reichartseder F, Zhao Y. Automated retrieval of standard diagnostic fetal cardiac ultrasound planes in the second trimester of pregnancy: a prospective evaluation of software. Ultrasound Obstet Gynecol 2008; 31:30-36.

90. Yeo L, Romero R. Fetal Intelligent Navigation Echocardiography (FINE): a novel method for rapid, simple, and automatic examination of the fetal heart. Ultrasound Obstet Gynecol 2013; 42:268-284.

91. Espinoza J, Lee W.xMatrix array and mechanical 4-dimensional volume transducers for standardized views of the fetal heart using an automated algorithm [abstract]. J Ultrasound Med 2011;30(suppl):S63.

92. Garcia M, Yeo L, Romero R, et al. Prospective evaluation of the fetal heart using Fetal Intelligent Navigation Echocardiography (FINE) [published online ahead of print August 17, 2015]. Ultrasound Obstet Gynecol. doi:10.1002/uog.15676.

93. Gonçalves LF, Espinoza J, Romero R, et al. Four-dimensional fetal echocardiography with spatiotemporal image correlation (STIC): a systematic study of standard cardiac views assessed by different observers. J Matern Fetal Neonatal Med 2005; 17:323-331.

94. Viñals F. Current experience and prospect of internet consultation in fetal cardiac ultrasound. Fetal Diagn Ther 2011;30:83-87.

95. Pinto NM, Nelson R, Puchalski M, Metz TD, Smith KJ. Cost-effectiveness of prenatal screening strategies for congenital heart disease. Ultrasound Obstet Gynecol 2014; 44:50-57.

96. Yeo L, Romero R. How to acquire cardiac volumes for sonographic examination of the fetal heart: part 2. J Ultrasound Med 2016; 35: 1043-1066.

97. Deng J. Terminology of three-dimensional and four-dimensional ultrasound imaging of the fetal heart and other moving body parts. Ultrasound Obstet Gynecol 2003; 22:336-344.

98. Falkensammer P.Spatio-temporal Image Correlation for Volume Ultrasound: Studies of the Fetal Heart. Zipf, Austria: GE Healthcare; 2005.

99. Nelson TR,PretoriusDH,SklanskyM,Hagen-AnsertS. Three-dimensional echocardiographic evaluation of fetal heart anatomy and function: acquisition, analysis, and display. J Ultrasound Med 1996; 15:1-9.

100. Bhat AH, Corbett VN, Liu R, et al. Validation of volume and mass assessments for human fetal heart imaging by 4-dimensional spatiotemporal image correlation echocardiography: in vitro balloon model experiments. JUltrasound Med 2004; 23:1151-1159.

101. Gonçalves LF, Espinoza J, KusanovicJP, Lee W, Romero R. Four-dimensional ultrasound examination of the fetal heart by spatiotemporal image correlation. In: Yagel S, Silverman NH, Gembruch U (eds). Fetal Cardiology: Embryology, Genetics, Physiology, Echocardiographic Evaluation, Diagnosis and Perinatal Management of Cardiac Diseases. New York, NY: Informa Healthcare USA Inc; 2009: 197-217.

102. Deng J, Rodeck CH. Current applications of fetal cardiac imaging technology. Curr Opin Obstet Gynecol2006; 18:177-184.

103. DeVore GR, Sklansky MS. Three-dimensional imaging of the fetal heart: current applications and future directions. Prog Pediatr Cardiol 2006; 22:9-29.
104. Merz E, Abramowicz JS. 3D/4D ultrasound in prenatal diagnosis: is it time for routine use? Clin Obstet Gynecol 2012; 55:336-351.

105. Benacerraf BR, Benson CB, Abuhamad AZ, et al. Three- and 4-dimensional ultrasound in obstetrics and gynecology: proceedings of the American Institute of Ultrasound in Medicine Consensus Conference. J Ultrasound Med 2005; 24:1587-1597.

106. Devore GR, Polanko B. Tomographic ultrasound imaging of the fetal heart: a new technique for identifying normal and abnormal cardiac anatomy. J Ultrasound Med 2005; 24:1685-1696.

107. Paladini D, Vassallo M, Sglavo G, Lapadula C, Martinelli P. The role of spatio-temporal image correlation (STIC) with tomographic ultrasound imaging (TUI) in the sequential analysis of fetal congenital heart disease. Ultrasound Obstet Gynecol 2006; 27:555-561.

108. Siwawong W, Tongprasert F, Srisupundit K, Luewan S, Tongsong T. Fetal cardiac circumference derived by spatiotemporal image correlation as a predictor of fetal hemoglobin Bart disease at midpregnancy. JUltrasound Med 2013; 32:1483-1488.

109. Yeo L, Romero R. Intelligent navigation to improve obstetrical sonography [published online ahead of print November 3, 2015]. Ultrasound Obstet Gynecol doi: 10.1002/uog.12562.

110. Tongsong T, Tongprasert F, Srisupundit K, Luewan S, Traisrisilp K. Cardio-STIC (spatio-temporal image correlation) as genetic ultrasound of fetal Down syndrome.J Matern Fetal Neonatal Med 2015; 28:1943-1949.

111. Yagel S, Valsky DV, Messing B. Detailed assessment of fetal ventricular septal defect with 4D color Doppler ultrasound using spatio-temporal image correlation technology. Ultrasound Obstet Gynecol 2005; 25:97-98.

112. Yagel S, Benachi A, Bonnet D, et al. Rendering in fetal cardiac scanning the intracardiac septa and the coronal atrioventricular valve planes. Ultrasound Obstet Gynecol 2006; 28:266-274.

113. BartlettJW, Frost C. Reliability, repeatability and reproducibility: analysis of measurement errors in continuous variables. Ultrasound Obstet Gynecol 2008; 31:466-475.

114. Bennasar M, Martínez JM, Gómez O, et al. Intra- and interobserver repeatability of fetal cardiac examination using four-dimensional spatiotemporal image correlation in each trimester of pregnancy. Ultrasound Obstet Gynecol 2010; 35:318-323.

115. Hamill N, Romero R, Hassan SS, et al. Repeatability and reproducibility of fetal cardiac ventricular volume calculations using spatiotemporal image correlation and virtual organ computer-aided analysis. J Ultrasound Med 2009; 28:1301-1311.

116. Gonçalves LF, Lee W, Espinoza J, Romero R. Examination of the fetal heart by four-dimensional (4D) ultrasound with spatio-temporal image correlation (STIC). Ultrasound Obstet Gynecol 2006; 27:336-348.

117. Yagel S, Cohen SM, Shapiro I, Valsky DV. Three- and four-dimensional ultrasound in fetal echocardiography: a new look at the fetal heart. In: Yagel S, Silverman NH, Gembruch U (eds). Fetal Cardiology: Embryology, Genetics, Physiology, Echocardiographic Evaluation, Diagnosis and Perinatal Management of Cardiac Diseases. New York, NY: Informa Healthcare USA Inc; 2009:219-237. 
118. Volpe P, Campobasso G, Stanziano A, et al. Novel application of 4D sonography with B-flow imaging and spatio-temporal image correlation (STIC) in the assessment of the anatomy of pulmonary arteries in fetuses with pulmonary atresia and ventricular septal defect. Ultrasound Obstet Gynecol 2006; 28:40-46.

119. Pooh RK, Korai A. B-flow and B-flow spatio-temporal image correlation in visualizing fetal cardiac blood flow. Croat Med J 2005; 46:808-811.

120. Viñals F, Pacheco V, Giuliano A. Fetal atrioventricular valve junction in normal fetuses and in fetuses with complete atrioventricular septal defect assessed by 4D volume rendering. Ultrasound Obstet Gynecol 2006; 28:2631.

121. Espinoza J, Hassan SS, Gotsch F, et al. A systematic approach to the use of the multiplanar display in evaluation of abnormal vascular connections to the fetal heart using 4-dimensional ultrasonography. J Ultrasound Med 2007; 26:1461-1467.

122. Yeo L, Romero R, Lee W. Assessment of cardiac geometry and stroke volumes by 4D fetal echocardiography. In: Rizzo G, Arduini D (eds).4D Fetal Echocardiography. Sharjah, United Arab Emirates: Bentham Science; 2010:160-177.

123. Simpson JM, CookA. Repeatability of echocardiographic measurements in the human fetus. Ultrasound Obstet Gynecol 2002; 20:332-339.

124. Simpson J. Echocardiographic evaluation of cardiac function in the fetus. Prenat Diagn 2004; 24:1081-1091.

125. Koestenberger M, Raith W, Ravekes W. Importance of quantifiable right heart systolic function evaluation using tricuspid annular plane systolic excursion (TAPSE) in fetuses and neonates. Ultrasound Obstet Gynecol 2013; 42:367.

126. Roberts D. How best to improve antenatal detection of congenital heart defects. Ultrasound Obstet Gynecol 2008; 32:846-848.

127. Votino C, Cos T,Abu-Rustum R, et al. Use of spatiotemporal image correlation at 11-14 weeks' gestation. Ultrasound Obstet Gynecol 2013; 42:669-678.

128. Wikipedia. Garbage in, garbage out. Wikipedia website. http:// en.wikipedia.org/wiki/Garbage_in,_garbage_out. Accessed January 24, 2016

129. Novaes JY, Zamith MM, Araujo Júnior E, de Sá Barreto EQ, Barros FS, Moron AF. Screening of congenital heart diseases by three-dimensional ultrasound using spatiotemporal image correlation: influence of professional experience. Echocardiography 2016; 33:99-104.

130. DeVore GR, Medearis AL, Bear MB, Horenstein J, Platt LD. Fetal echocardiography: factors that influence imaging of the fetal heart during the second trimester of pregnancy. J Ultrasound Med 1993; 12:659-663.

131. Viñals F, Ascenzo R, Naveas R, Huggon I, Giuliano A. Fetal echocardiography at $11+0$ to $13+6$ weeks using four-dimensional spatiotemporal image correlation telemedicine via an Internet link: a pilot study. Ultrasound Obstet Gynecol 2008; 31:633-638.

132. Dan-dan W, Xiao-peng D, Wei C. The value of spatiotemporal image correlation technique in the diagnosis of fetal ventricular septal defect. Arch Gynecol Obstet 2011; 283:965-969.
133. Simioni C, Araujo Júnior E, Martins WP, et al. Fetal cardiac output and ejection fraction by spatio-temporal image correlation (STIC): comparison between male and female fetuses. Rev Bras Cir Cardiovasc 2012; 27:275-282.

134. Rocha LA, Rolo LC, Barros FS, Nardozza LM, Moron AF, Araujo Júnior E. Assessment of quality of fetal heart views by 3D/4D ultrasonography using spatio-temporal image correlation in the second and third trimesters of pregnancy. Echocardiography 2015; 32:1015-1021.

135. Tongsong T, Wanapirak C, PiyamongkolW, et al. Fetal ventricular shortening fraction in hydrops fetalis. Obstet Gynecol 2011; 117:84-91.

136. Zhang Y, Ding C, Fan M, et al. Evaluation of normal fetal pulmonary veins using B-flow imaging with spatiotemporal image correlation and by traditional color Doppler echocardiography. Prenat Diagn 2012; 32:11861191.

137. Turan S, Turan OM, Desai A, Harman CR, Baschat AA. First-trimester fetal cardiac examination using spatiotemporal image correlation, tomographic ultrasound and color Doppler imaging for the diagnosis of complex congenital heart disease in high-risk patients. Ultrasound Obstet Gynecol 2014; 44:562-567.

138. Zidere V, Bellsham-Revell H, Persico N, Allan LD. Comparison of echocardiographic findings in fetuses at less than 15 weeks' gestation with later cardiac evaluation. Ultrasound Obstet Gynecol 2013; 42:679-686.

139. Gardiner HM. First-trimester fetal echocardiography: routine practice or research tool? Ultrasound Obstet Gynecol 2013; 42:611-612.

140. Sotiriadis A, Papatheodorou S, Eleftheriades M, Makrydimas G. Nuchal translucency and major congenital heart defects in fetuses with norma karyotype: a meta-analysis. Ultrasound Obstet Gynecol2013; 42:383-389.

141. Foy PM, Wheller JJ, Samuels P, Evans KD. Evaluation of the fetal heart at 14 to 18 weeks' gestation in fetuses with a screening nuchal translucency greater than or equal to the 95th percentile. J Ultrasound Med 2013; 32:1713-1719.

142. Wiechec M, Knafel A, Nocun A. Prenatal detection of congenital heart defects at the 11- to 13-week scan using a simple color Doppler protocol including the 4-chamber and 3-vessel and trachea views. J Ultrasound Med 2015; 34:585-594.

143. Nemescu D, Onofriescu M. Factors affecting the feasibility of routine firsttrimester fetal echocardiography. J Ultrasound Med 2015; 34:161-166. 